\title{
Sleep Duration May Not Have Any Effect on The Risk of Stroke: Insights from Mendelian Randomization and Prospective Cohort Studies
}

\section{Type}

Research paper

\section{Keywords}

sleep duration, Mendelian Randomization, Stroke, Ischemic stroke

\begin{abstract}
Introduction

Due to contentious associations between sleep and stroke risk we performed a meta-analysis of cohort studies and utilized Mendelian randomization (MR).

Material and methods

For the meta-analysis we pooled prospective studies and then reviewed the largest genome-wide association studies regarding self-reported or accelerometer-derived sleep duration with stroke [ischemic (IS), cardioembolic (CES), large artery (LAS), small vessel (SVS)]. Inverse variance weighted method (IVW), weighted median (WM)-based method, MR-Egger and MR-Pleiotropy RESidual Sum and Outlier (PRESSO) were performed. To determine the impact of single nucleotide polymorphisms (SNPs) leave-one-out method was applied.
\end{abstract}

\section{Results}

Pooled prospective studies demonstrated shorter $(<7 \mathrm{~h})$ [ $\mathrm{n}=25$ studies, $12=71.4, \mathrm{p}<0.001$; risk ratio (RR): 1.18, 95\% Cl: 1.08-1.30, $p<0.001$ ] and longer ( $>8 \mathrm{~h}$ ) [ $\mathrm{n}=16$ studies, $\mathrm{I} 2=53.6, p<0.001$; RR: $1.38,95 \% \mathrm{Cl}: 1.24-1.53, \mathrm{p}<0.001$ ] sleep increased stroke risk (compared with 7-8h), but were subject to high levels of heterogeneity. In MR, self-reported sleep duration had no significant effect on IS (IVW: beta $=-0.031, p=0.747$ ), CES (IVW: beta $=-0.039, p=0.849$ ), LAS (IVW: beta $=-0.246, p=$ 0.328 ) and SVS (IVW: beta $=-0.102, p=0.667$ ) risk. This was also observed for short and long accelerometer-derived sleep (all $p>0.126$ ). Estimated associations had no significant heterogeneity and MR-PRESSO revealed no outliers. There was low likelihood of pleiotropy (all estimations $p$ $>0.539$ ) and associations were not driven by single SNPs.

\section{Conclusions}

Meta-analysis revealed shorter and longer sleep increased total stroke risk, but with high heterogeneity. MR analysis showed no causal associations between sleep duration and stroke risk. 


\section{Sleep Duration May Not Have Any Effect on The Risk of Stroke: Insights from Mendelian Randomization and Prospective Cohort Studies}

Running title: Sleep duration and the risk of stroke

\section{ABSTRACT:}

Introduction: Due to contentious associations between sleep and stroke risk we performed a metaanalysis of cohort studies and utilized Mendelian randomization (MR).

Material and Methods: For the meta-analysis we pooled prospective studies and then reviewed the largest genome-wide association studies regarding self-reported or accelerometer-derived sleep duration with stroke [ischemic (IS), cardioembolic (CES), large artery (LAS), small vessel (SVS)]. Inverse variance weighted method (IVW), weighted median (WM)-based method, MR-Egger and MR-Pleiotropy RESidual Sum and Outlier (PRESSO) were performed. To determine the impact of single nucleotide polymorphisms (SNPs) leave-one-out method was applied.

Results: Pooled prospective studies demonstrated shorter $(<7 \mathrm{~h})\left[\mathrm{n}=25\right.$ studies, $\mathrm{I}^{2}=71.4, \mathrm{p}<0.001$; risk ratio (RR): 1.18, 95\% Cl: 1.08-1.30, $p<0.001$ ] and longer (>8h) [ $n=16$ studies, $l^{2}=53.6, p<0.001 ; R R: 1.38$, 95\% Cl: 1.24-1.53, $\mathrm{p}<0.001$ ] sleep increased stroke risk (compared with 7-8h), but were subject to high levels of heterogeneity. In MR, self-reported sleep duration had no significant effect on IS (IVW: beta = 0.031, p = 0.747), CES (IVW: beta $=-0.039, p=0.849$ ), LAS (IVW: beta $=-0.246, p=0.328$ ) and SVS (IVW: beta $=-0.102, p=0.667$ ) risk. This was also observed for short and long accelerometer-derived sleep (all $p>0.126$ ). Estimated associations had no significant heterogeneity and MR-PRESSO revealed no outliers. There was low likelihood of pleiotropy (all estimations $p>0.539$ ) and associations were not driven by single SNPs.

Conclusions: Meta-analysis revealed shorter and longer sleep increased total stroke risk, but with high heterogeneity. MR analysis showed no causal associations between sleep duration and stroke risk.

Keywords: Mendelian Randomization, sleep duration, Stroke, Ischemic stroke 


\section{INTRODUCTION:}

Stroke is a major cardiovascular (CV) event that can lead to brain tissue damage and functional disability, as well as death (1). Due to these detrimental effects of stroke, evaluating stroke risk factors can be of high importance to prevent this potentially fatal CV disease (CVD) or determine its outcomes.

Sleep duration is recognised as a major factor for a healthier lifestyle and improved cardiac function (2). In this context, sleeping patterns (i.e. short or long duration) have been closely linked to morbidity and mortality $(3,4)$, as well as with chronic cardiometabolic disease, including obesity, hypertension, diabetes, respiratory diseases, coronary heart disease and reduced renal function (CHD) (2, 5-9). There are several parameters that can influence sleep duration, such as cultural, social, psychological, behavioral, pathophysiological and environmental factors $(10,11)$.

Considering the potential harmful effects of unfavourable sleep duration on public health, it is clinically important to establish whether causality exists between sleep duration and CVD. Recent studies showed that sleep duration may be a risk factor for CVD (12). Both short ( $<7 \mathrm{~h}$ ) and long ( $>8 \mathrm{~h}$ ) sleep duration have been related to a greater risk of myocardial infarction (MI) (12-14). However, the National Health and Nutrition Examination Survey (NHANES), the Nurses' Health Study (NHS) and the Monitoring Trends and Determinants on Cardiovascular Disease (MONICA) Augsburg cohort study reported inconsistent findings regarding the association between sleep duration and CHD risk $(5,15,16)$. A prospective study of 461,347 UK Biobank (UKB) individuals found that short and long sleep duration had a 20 and 34\% higher risk of incident MI compared with sleeping 6 - 9 h, respectively, independent of individuals' genetic predisposition to CHD (17).

With regards to stroke, epidemiological studies showed a significant association between long sleep duration and stroke risk $(16,18,19)$. In contrast, no significant relationship between sleep duration and stroke risk was observed in another prospective cohort study of 2,282 males (20). Previous systematic reviews evaluated the links between sleep duration, CV outcomes and all-cause death (11, 12), reporting that both short and long duration of sleep were associated with a greater risk of total mortality and/or CVD morbidity, including CHD and stroke. However, the high heterogeneity between the studies was a limitation, making it difficult to draw safe conclusions or support causal inference.

Given the controversial evidence on the potential role of sleep duration on CVD outcomes and its importance for public health, there is an unmet need to elucidate this link in terms of developing effective approaches (including drug therapy) for stroke prevention and management. Epidemiological 
studies provide only simple estimates of the associations between sleep duration and disease risk, and they are prone to bias. Therefore, Mendelian Randomization (MR) studies can evaluate these relationships with the use of a large-scale genetic data [involving single nucleoid polymorphisms (SNPs) as proxies for lifetime exposure] to provide a more reliable indication of a causal role of sleep duration on stroke risk (21).

In the present study, a comprehensive systematic review and meta-analysis was conducted to examine the associations between sleep duration and the risk of total stroke based on data from prospective cohort studies. Second, a MR analysis was performed to assess the associations between sleep duration ( $<7$ vs $>8$ h) and different types of stroke, surpassing the limitations of the epidemiological studies (i.e. residual bias, confounding factors and reverse causation) (22).

\section{METHODS}

\section{[A] Cohort studies}

\section{Literature search and study selection}

The meta-analysis was designed, conducted and reported, according to the Meta-analysis Of Observational Studies in Epidemiology (MOOSE) guidelines (23) (the MOOSE checklist is provided in Supplementary Table 1). The primary exposure of interest was sleep duration and stroke was the primary outcome. Prospective cohort studies published up to 31 October 2019 (without language restriction) were searched using the PubMed, Embase, and Scopus databases; the query search syntax is shown in Supplementary Table 2. When required, further searches were performed regarding the reference list of eligible articles, previous reviews or meta-analyses, as well as email correspondence with authors for additional data.

\section{Study Selection}

Predefined inclusion criteria (see below) were used to determine prospective cohort studies regarding the association between sleep duration and stroke risk. Duplicates were removed and then titles and abstracts were screened by two reviewers (MM and NS). To avoid bias, both reviewers were blinded to the names, qualifications or the affiliations of the study authors. The overall agreement between both reviewers was excellent (Kappa index: $0.91 ; p<0.001$ ) and a meeting was held to resolve any disagreements between reviewers prior to articles being retrieved (a flow chart outlining this process is available in Figure 1). 
We included studies if the following criteria were met: (1) the topic of interest was sleep duration; (2) the studies were population-based cohort studies which reported stroke risk data; (3) relative risk $(\mathrm{RR})$, hazard ratio (HR) or odds ratio (OR) estimates with $95 \%$ confidence interval $(\mathrm{Cl})$ adjusted for multivariable factors were available or could be calculated.

We excluded studies if the following criteria were met: (1) narrative reviews, reviews, comments, opinion papers, methodological reports, editorials, letters, or any other publications lacking primary data and/or specific descriptions of the methods which were used; (2) not population-based cohort studies; (3) RR, HR or OR estimates with $95 \% \mathrm{Cl}$ were either not available or could not be calculated.

\section{Data extraction and management}

The full text of studies meeting the inclusion criteria were retrieved and eligibility was determined via screening by two reviewers (MM and NS). An assessment of study quality was determined using the Newcastle-Ottawa Scale (NOS) (Supplementary Table 3) (24). Furthermore, sources of funding pertaining to each eligible study was investigated. Following an assessment of methodological quality, both reviewers (MM and NS) extracted data using a purpose-designed data extraction form. Using this data the most important results from each study were summarized by each reviewer independently. Both summaries were then compared, and a third reviewer (MB) to then consulted to resolve any differences. Any necessary additional calculations regarding the study data, were performed by the first reviewer (MM) and verified by the second reviewer (NS). Specific information which was extracted from each eligible study included: author, year and references, study name, proportion male, mean age, follow-up time (Years), assessment of sleep duration, main confounders (Table 1).

\section{Data synthesis and statistical analyses}

For those studies which reported results from a variety of multivariable-adjusted models, only the model with the most confounding factors was incorporated into the meta-analysis. A random-effect model was employed to generate pooled $\mathrm{RRs}, 95 \% \mathrm{Cl}$ and $\mathrm{p}$ values for heterogeneity. RRs comparing the highest and lowest categories were combined across studies to determine summary associations. The extent of heterogeneity across studies was examined using the $I^{2}$ test (25-27); an $I^{2}>50 \%$ with a twosided $p<0.05$ indicated significant heterogeneity $(25-27)$.

\section{Publication bias}


To determine potential publication bias Begg's funnel plot asymmetry was investigated by visual inspection and Begg's rank correlation and Egger's weighted regression tests were also used (28). To adjust for the effects of publication bias the Duval and Tweedie trim method was utilized (28). Comprehensive Meta-Analysis (CMA) V3 software (Biostat, NJ) was used to conduct the meta-analysis (29).

\section{[B] Mendelian Randomization}

\section{Study design}

For our MR study a two-sample MR study design was used and the largest genome wide association studies (GWAS) on sleep duration (objectively and subjectively measured) and interested outcomes were used to obtain summary statistics. We then applied methods to estimate the unbiased effect of sleep traits on the risk of different types of stroke [i.e. ischemic (IS), cardioembolic (CES), large artery (LAS), small vessel (SVS)].

\section{Genetic instruments for sleep duration}

Procedures pertaining to genotyping, quality control, and imputation which have been used in the UKB have been previously described (30). From the largest GWAS, 78 SNPs were identified to be associated with sleep duration (self-reported) among individuals of European ancestry $(n=446,118)$ (Supplementary Table 4) (31). We hypothesized that the link between sleep duration and stroke risk might be non-linear; therefore, we also used data pertaining to 27 SNPs associated with short sleep $(<7$ $h ; n=106,192$ cases/305,742 controls) and 8 SNPs related to long sleep (>8 h; $n=34,184$ cases/305,742 controls) in the two-sample MR analysis (31). We applied on the GWAS ( $n=85,205$ participants), performed in the UKB for genetic variants known to be robustly associated with accelerometer-driven sleep trait data (nocturnal sleep duration), which were compared with causal estimates obtained by the genetic variants associated with self-reported sleep duration (Supplementary Table 4). Data on this procedure has been previously published (32). We identified proxy SNPs with a minimum linkage disequilibrium (LD) $\mathrm{r} 2=0.8$ if a SNP was unavailable for the outcome GWAS summary statistics. We restricted our genetic instrument to independent SNPs not in linkage disequilibrium $(p=0.0001)$ to minimize bias in effect estimates induced by correlation between SNPs. Herein we will refer to a set of SNPs which act as a proxy for sleep duration as "genetic instruments."

\section{Association of genetic instruments with outcome}


We utilized the largest available extensively genotyped dataset, i.e. the METASTROKE, a collaboration of the International Stroke Genetics Consortium to determine genetic associations with different ischemic stroke types (33). This dataset included GWAS data on 34,217 IS cases and 404,630 controls of European ancestry from across 15 studies [subtyped into SVS $(n=5,386)$, LAS $(n=4,373)$ and CES $(n=7,193)]$ (33). The majority of the IS cases involved brain imaging confirmation. Approximately $50 \%$ of the cases had IS subtype information (2,365 CES, 2,167 LAS and 1,894 SVS cases) based on the Trial of ORG 10172 in Acute Stroke Treatment (TOAST) classification (34). Additional phenotype descriptions and details of individual studies included in the dataset are available elsewhere (33).

\section{MR analysis}

The effect of 5 instruments were combined using the inverse variance weighted (IVW) method as implemented using the TwoSampleMR package within the R environment [version 3.4.2 R Core Team (2017)]. Heterogeneity was assessed by the Q value for IVW. The potential effects of pleiotropic variants were addressed on the final effect estimate by performing a sensitivity analysis, including weighted median (WM) and MR-egger tests (35). To identify instruments which might drive the MR results sensitivity analysis was conducted using the leave-one-out method. The WM estimate provides correct estimates if SNPs accounting for $\geq 50 \%$ of the weight are valid instruments. To weight the variants inverse variance was used and to estimate Cis bootstrapping was applied (35). MR-egger analysis can define estimates even under the assumption that all SNPs are invalid instruments if the assumption of instrument strength independent of direct effect (InSIDE) is satisfied (35). That said, the InSIDE assumption is not easy to verify. The $p$ value of the intercept term from the MR-Egger analysis was used to assess the average directional pleiotropy across genetic variants (35). Causal estimates in MR-Egger are less precise than those obtained by using IVW MR (36). Indeed, due to its lower statistical power the analysis using MR-Egger has a lower false-positive but a higher false-negative rate than IVW (37).

The $Q^{\prime}$ heterogeneity statistic (38) and the MR pleiotropy residual sum and outlier (MR-PRESSO) test (38) were both used to assess heterogeneity between individual genetic variant estimates. The $Q^{\prime}$ statistic uses modified $2^{\text {nd }}$ order weights that are derived from a Taylor series expansion and considers the uncertainty in both numerator and denominator of the instrumental variable ratio (38). The MRPRESSO framework detects and removes effect estimates which are outliers by regressing the variantoutcome associations on variant-exposure associations. Then a global heterogeneity test was implemented which compares the observed distance between residual sums of squares of all variants to the regression line with the distance expected under the null hypothesis of no pleiotropy (39). In 
addition to this, we also applied an MR-Robust Adjusted Profile Score (RAPS) to correct for pleiotropy using robust adjusted profile scores. RAPS can also provide an unbiased causal estimate in the presence of weak instruments. We considered all results which were causal estimates that agreed in direction and magnitude across MR methods, as well as passing nominal significance in the IVW MR analysis and which did not, after applying heterogeneity tests, show evidence of bias from horizontal pleiotropy. To assess the instrumental variable analysis "exclusion-restriction" assumption, we used Ensembl release (http://useast.ensembl.org/index.html), which contains a base of SNP phenotypes.

\section{Ethics}

The present meta-analysis and MR analysis used published or publicly available summary data without involvement of participants or original data collection. Ethical approval for each of the studies included in these analyses can be found in the original publications (including informed consent from each participant). The study conforms to the ethical guidelines of the 1975 Declaration of Helsinki.

\section{RESULTS:}

\section{Meta-analysis and systematic review}

Of 44 eligible full articles, 12 articles with 594,632 participants met the inclusion criteria (Figure 1). The included studies were published between 1997 (16) and 2016 (40), from different countries, including the United States of America (3 studies) (16, 19, 41), UK (1 study) (42), Japan (2 studies) (20, 43), Germany (2 studies) $(44,45)$, Australia (1 study) $(46)$, China (2 studies) $(40,47)$ and Sweden $(1$ study) (48). A total of 3 studies presented sex-specific results, one study involved only men (20) and 2 studies only women $(19,47)$. The age of the participants ranged from $44(20)$ to 63 years $(46)$ and the follow up duration from $2(41)$ to 14 years $(20,44)$. Basic characteristics of the 12 prospective cohort studies are shown in Table 1.

\section{Sleep duration and risk of stroke}

Compared with participants sleeping 7 - $8 \mathrm{~h}$ per night (reference group), individuals with $<7 \mathrm{~h}$ sleep had a significantly higher risk of stroke (RR: 1.18, 95\%Cl: $1.08-1.30, p<0.001, n=25$ studies, Figure 2), but with a high level of heterogeneity $\left(I^{2}=71.4, p<0.001\right)$. In gender analysis, stroke risk was insignificantly increased by $18 \%$ in men (RR: $1.18,95 \% \mathrm{Cl}$ : $0.88-1.58, p=0.263, n=4$ studies, $I^{2}=43.5, p$ $=0.150$ ) and by $20 \%$ in women (RR: $1.20,95 \% \mathrm{Cl}: 0.98-1.46, p=0.064, n=7$ studies, $I^{2}=79.3, p<0.001$ ). 
We then pooled the risk of stroke for those with $\leq 5 \mathrm{~h}$ of sleep who had a significantly greater stroke risk compared with the reference group (RR: $1.34,95 \% \mathrm{Cl}: 1.17-1.53, \mathrm{p}<0.001, \mathrm{n}=13$ studies, Figure 3) but again with a high level of heterogeneity $\left(I^{2}=58.4, p<0.001\right)$. No association was observed for participants sleeping $6 \mathrm{~h}$ per night (compared with the reference group) (RR: 1.07, 95\%Cl: $0.98-1.18, \mathrm{p}$ $=0.110, \mathrm{n}=12$ studies, $\mathrm{I}^{2}=52.6, \mathrm{p}=0.016$, Figure 4). Longer sleep duration (i.e. $>8 \mathrm{~h}$ ) was related to an increased stroke risk compared with 7 - 8 h sleep (RR: $1.38,95 \% \mathrm{Cl}$ : $1.24-1.53, \mathrm{p}<0.001, \mathrm{n}=16$ studies, $\mathrm{I}^{2}=53.6, \mathrm{p}<0.001$, Figure 5). In gender analysis, the risk was $22 \%$ in men (RR: $1.22,95 \% \mathrm{Cl}: 1.00-1.49, \mathrm{p}$ $=0.042, \mathrm{n}=3$ studies, $\mathrm{I}^{2}=0.0, \mathrm{p}=0.398$ ) and $24 \%$ in women (RR: $1.24,95 \% \mathrm{Cl}: 0.91-1.67, \mathrm{p}=0.159, \mathrm{n}=$ 5 studies, $\left.\mathrm{I}^{2}=81.6, \mathrm{p}<0.001\right)$.

Compared with the reference group, $>9 \mathrm{~h}$ of sleep also significantly increased stroke risk (RR: 1.35, $95 \% \mathrm{Cl}: 1.22-1.50, \mathrm{p}<0.001, \mathrm{n}=13$ studies, $\left.\mathrm{I}^{2}=41.5, \mathrm{p}=0.043\right)$, whereas $10 \mathrm{~h}$ of sleep did not affect the risk (RR: $1.40,95 \% \mathrm{Cl}$ : $0.95-2.07, \mathrm{p}=0.082, \mathrm{n}=3$ studies, $\mathrm{I}^{2}=75.7, \mathrm{p}=0.016$ ). It should be noted that in all the above comparisons, there was a high level of heterogeneity between the studies.

\section{Sensitivity analysis}

In the leave-one-out sensitivity analyses, the pooled effect estimates remained similar for the effect of both shorter and longer (in comparison with the reference group) sleep duration (RR: $1.18,95 \% \mathrm{Cl}$ : $1.08-1.30$, and $1.38,95 \% \mathrm{Cl}: 1.24-1.53$, respectively). This confirms that the significant difference between the studied groups is the overall effect of all included studies.

\section{Publication bias}

Egger's linear regression also supported the absence of any publication bias (intercept $=2.33,95 \% \mathrm{Cl}$ $=1.77,-5.22, \mathrm{p}=0.450$ ). Furthermore, Begg's rank correlation test (Kendall's Tau with continuity correction $=0.412, z=0.832, p=0.452$ ) was not indicative for publication bias.

\section{Mendelian Randomization}

The list of all instruments associations for sleep duration (subjectively and objectively assessed) is shown in Supplementary Table 4. The results, expressed as beta-coefficient for sleep duration per one standard deviation (SD) increase in outcomes (i.e. stroke risk) are presented in Tables 2-5. Self-reported sleep duration had no significant effect on the risk of IS (IVW: beta $=-0.031, p=0.747$ ), CES (IVW: beta = -0.039, $p=0.849$ ), LAS (IVW: beta $=-0.246, p=0.328$ ) and SVS (IVW: beta $=-0.102, p=0.667$ ) (Table 2). The same pattern was observed for the accelerometer recorded sleep duration (for IS IVW: beta $=0.033$, 
$p=0.739 ;$ for CES IVW: beta $=-0.072, p=0.713$; for LAS IVW: beta $=0.109, p=0.664$ and for SVS IVW: beta $=0.367, p=0.149)($ Table 3).

Short sleep duration had also no significant impact on the risk of different strokes (for IS IVW: beta $=0.343, p=0.335$, for CES IVW: beta $=-0.384, p=0.614$, for LAS IVW: beta $=1.321, p=0.156$ and for SVS IVW: beta $=-0.009, p=0.990$ ) (Table 4). Similar results were found for long sleep duration (for IS IVW: beta $=-0.219, p=0.805$, for CES IVW: beta $=1.895, p=0.279$, for LAS IVW: beta $=2.126, p=0.389$ and for SVS IVW: beta $=1.369, \mathrm{p}=0.508)($ Table 5)

None of the IWV estimates showed any heterogeneity (Tables 2-5). The MR-PRESSO analysis also did not show any possibility of outlier for all the estimates. Furthermore, the pleiotropy test, with very negligible intercept and insignificant $p$ value, also indicated low chance of the pleiotropy for all estimations (all $p>0.539$, Tables 2-5). The results of the MR-RAPS were identical with the IVW estimates in almost all cases, highlighting again a low likelihood of pleiotropy. The results of the leave-one-out method demonstrated that the observed associations were not driven by single SNPs.

\section{DISCUSSION:}

In the present study, we performed a comprehensive systematic review and meta-analysis of the available prospective cohort studies, as well as conducted a MR analysis to evaluate the potential effects of sleep duration on the risk of stroke in a causal model. By pooling prospective studies, we showed that shorter and longer sleep duration might be considered as a significant risk factor for stroke. However, these results were subjected to a high level of heterogeneity, thus minimizing their validity, and highlighting the need for further, more reliable, statistical analyses. In this context, the MR analysis showed no association between sleep duration and the risk of different types of stroke, with low levels of heterogeneity and pleiotropy.

Sleep duration is generally not regarded as a traditional risk factor for CVD, but previous studies reported a negative association between short and long sleep duration with CVD morbidity (48) and CVD risk factors (49). Indeed, sleep duration and circadian rhythm disorders, as well as insomnia have been related to stroke $(49,50)$ with approximately half of stroke survivors potentially having insomnia $(50)$.

Growing evidence suggests that short and long sleep duration may be linked to adverse health outcomes, including total mortality $(3,4), \operatorname{CVD}$ events $(4,15,18,51)$, diabetes $(52)$ and hypertension (7, 8). The exact underlying mechanisms of a potential association between sleep duration and CVD have not been established yet. In this context, short sleep duration may increase leptin and ghrelin levels (53), leading to increased appetite and caloric intake and reduced energy expenditure, both of which 
may contribute to the development of obesity (54). Increased cortisol secretion and changes in growth hormone metabolism have also been reported in relation to short sleep duration (55), as well as lowgrade inflammation, which can predispose to CVD $(55,56)$. Furthermore, epidemiological studies have shown that short sleep duration may be related to higher levels of hemoglobin A1C (56), total cholesterol, triglycerides and blood pressure (57), which are all CVD risk factors. Sleep disorders have also been suggested to affect the outcomes of CVD events (58)

Depressive symptoms, low socio-economic status, unemployment and low level of physical activity have been linked to long sleep duration and may confound the relationship of sleep duration with morbidity and mortality $(59,60)$. In this context, the observed harmful effects of longer sleep were confounded by depression or socioeconomic status (61).

One previous meta-analysis ( $n=74$ studies; 3,340,684 participants) reported no significant differences in stroke events in relation to self-reported sleep duration shorter or longer than $7 \mathrm{~h}$, whereas a moderate increase in stroke mortality was observed in those sleeping $\geq 7 \mathrm{~h}(2)$. A study in 2,282 males healthy aged 35 - 54 years found no significant association between any sleep duration and stroke risk during 14 years of follow-up, after adjustment for potential confounders, including traditional CVD risk factors and working status (20). In contrast, another systemic review and meta-analysis of 15 prospective studies ( $n=474,684$ male and female individuals; follow-up 6.9 - 25 years) reported that both short and long sleep duration were significantly related to a greater risk of stroke (12).

Ikehara et al. performed a study which included 98,643 individuals (41,489 men and 57,145 women) aged 40 to 79 years and found that long sleep duration ( $\geq 10 \mathrm{~h}$ ) was associated with a 1.5 to 2fold increased mortality from total and ischemic stroke compared with $7 \mathrm{~h}$ of sleep (18). In a 10-year follow up of the NHANES cohort $(n=7844$; aged $\geq 32$ years), long ( $>8 \mathrm{~h}$ ) sleep duration was related to a higher risk of stroke compared with the reference group (6 to $8 \mathrm{~h}$ of sleep) (16). In another metaanalysis of 16 prospective studies, the lowest stroke risk was observed in those sleeping $7 \mathrm{~h}$ per night; of note, in cases of $>7 \mathrm{~h}$ sleep, total stroke risk was increased by $13 \%$ for every $1 \mathrm{~h}$ increase in sleep duration (61). Furthermore, the Women's Health Initiative Observational Study reported that long sleep duration was significantly associated with ischemic stroke among postmenopausal women (19). In motor-impaired, right hemisphere stroke patients, sleep latencies were longer and sleep efficiency was worse in comparison to age-and sex-matched controls (62). Furthermore, in a Taiwan administrative data study which included 21,438 participants with insomnia and 64,314 age and sex-matched without insomnia, those with insomnia had a $54 \%$ increased risk of stroke (63). 
The present findings should be extrapolated with caution since our analysis has some limitations. In this context, we were unable to thoroughly evaluate individual-level confounding factors. Although we used different methods in our MR analysis, there might be still a chance of horizontal pleiotropy. Furthermore, a high level of heterogeneity was observed in the present meta-analysis. Despite this, the present analysis has strengths, including the fact that the MR analysis reduced the risk of potential reverse causation and genotypes were assumed to be randomly distributed with respect to confounders.

In conclusion, pooled data from prospective cohort studies showed that sleep duration may increase the risk of stroke, but the high level of heterogeneity observed between studies significantly minimizes the validity of these findings. Furthermore, the MR analysis reported no associations between sleep duration and the risk of different ischemic stroke types, with a low level of heterogeneity and pleiotropy. 


\section{REFERENCES:}

1. Prevention S. Guidelines for medical treatment for stroke prevention. Ann Intern Med. 1994;121:54-5.

2. Kwok CS, Kontopantelis E, Kuligowski G, Gray M, Muhyaldeen A, Gale CP, et al. Self-reported sleep duration and quality and cardiovascular disease and mortality: a dose-response meta-analysis. Journal of the American Heart Association. 2018;7(15):e008552.

3. Kripke DF, Garfinkel L, Wingard DL, Klauber MR, Marler MR. Mortality associated with sleep duration and insomnia. Archives of general psychiatry. 2002;59(2):131-6.

4. Ferrie JE, Shipley MJ, Cappuccio FP, Brunner E, Miller MA, Kumari M, et al. A prospective study of change in sleep duration: associations with mortality in the Whitehall II cohort. Sleep. 2007;30(12):1659-66.

5. Ayas NT, White DP, Manson JE, Stampfer MJ, Speizer FE, Malhotra A, et al. A prospective study of sleep duration and coronary heart disease in women. Archives of internal medicine. 2003;163(2):2059.

6. Ayas NT, White DP, Al-Delaimy WK, Manson JE, Stampfer MJ, Speizer FE, et al. A prospective study of self-reported sleep duration and incident diabetes in women. Diabetes care. 2003;26(2):380-4.

7. Cappuccio FP, Stranges S, Kandala N-B, Miller MA, Taggart FM, Kumari M, et al. Gender-specific associations of short sleep duration with prevalent and incident hypertension: the Whitehall II Study. Hypertension. 2007;50(4):693-700.

8. Gangwisch JE, Heymsfield SB, Boden-Albala B, Buijs RM, Kreier F, Pickering TG, et al. Short sleep duration as a risk factor for hypertension: analyses of the first National Health and Nutrition Examination Survey. hypertension. 2006;47(5):833-9.

9. Mazidi M, Shekoohi N, Katsiki N, Banach M. Longer sleep duration may negatively affect renal function. Int Urol Nephrol. 2021;53(2):325-32.

10. Cappuccio FP, Taggart FM, Kandala N-B, Currie A, Peile E, Stranges S, et al. Meta-analysis of short sleep duration and obesity in children and adults. Sleep. 2008;31(5):619-26.

11. Cappuccio FP, D'Elia L, Strazzullo P, Miller MA. Sleep duration and all-cause mortality: a systematic review and meta-analysis of prospective studies. Sleep. 2010;33(5):585-92.

12. Cappuccio FP, Cooper D, D'elia L, Strazzullo P, Miller MA. Sleep duration predicts cardiovascular outcomes: a systematic review and meta-analysis of prospective studies. European heart journal. 2011;32(12):1484-92.

13. Jike $\mathrm{M}$, Itani O, Watanabe N, Buysse DJ, Kaneita Y. Long sleep duration and health outcomes: A systematic review, meta-analysis and meta-regression. Sleep Medicine Reviews. 2018;39:25-36.

14. Itani O, Jike M, Watanabe N, Kaneita Y. Short sleep duration and health outcomes: a systematic review, meta-analysis, and meta-regression. Sleep medicine. 2017;32:246-56.

15. Meisinger C, Heier M, Löwel H, Schneider A, Döring A. Sleep duration and sleep complaints and risk of myocardial infarction in middle-aged men and women from the general population: the MONICA/KORA Augsburg cohort study. Sleep. 2007;30(9):1121-7.

16. Qureshi Al, Giles WH, Croft JB, Bliwise DL. Habitual sleep patterns and risk for stroke and coronary heart disease: a 10-year follow-up from NHANES I. Neurology. 1997;48(4):904-10.

17. Daghlas I, Dashti HS, Lane J, Aragam KG, Rutter MK, Saxena R, et al. Sleep Duration and Myocardial Infarction. Journal of the American College of Cardiology. 2019;74(10):1304-14.

18. Ikehara S, Iso H, Date $C$, Kikuchi S, Watanabe $Y$, Wada $Y$, et al. Association of sleep duration with mortality from cardiovascular disease and other causes for Japanese men and women: the JACC study. Sleep. 2009;32(3):295-301. 
19. Chen J-C, Brunner RL, Ren H, Wassertheil-Smoller S, Larson JC, Levine DW, et al. Sleep duration and risk of ischemic stroke in postmenopausal women. Stroke; a journal of cerebral circulation. 2008;39(12):3185.

20. Hamazaki Y, Morikawa Y, Nakamura K, Sakurai M, Miura K, Ishizaki M, et al. The effects of sleep duration on the incidence of cardiovascular events among middle-aged male workers in Japan. Scandinavian journal of work, environment \& health. 2011:411-7.

21. Davies NM, Holmes MV, Davey Smith G. Reading Mendelian randomisation studies: a guide, glossary, and checklist for clinicians. BMJ (Clinical research ed). 2018;362:k601.

22. Smith GD, Ebrahim S. 'Mendelian randomization': can genetic epidemiology contribute to understanding environmental determinants of disease? International journal of epidemiology. 2003;32(1):1-22.

23. Stroup DF, Berlin JA, Morton SC, Olkin I, Williamson GD, Rennie D, et al. Meta-analysis of observational studies in epidemiology: a proposal for reporting. Meta-analysis Of Observational Studies in Epidemiology (MOOSE) group. Jama. 2000;283(15):2008-12.

24. Stang A. Critical evaluation of the Newcastle-Ottawa scale for the assessment of the quality of nonrandomized studies in meta-analyses. European journal of epidemiology. 2010;25(9):603-5.

25. Ferretti G, Bacchetti T, Sahebkar A. Effect of statin therapy on paraoxonase-1 status: A systematic review and meta-analysis of 25 clinical trials. Progress in lipid research. 2015;60:50-73.

26. Sahebkar A. Are curcuminoids effective C-reactive protein-lowering agents in clinical practice? Evidence from a meta-analysis. Phytotherapy research : PTR. 2014;28(5):633-42.

27. Sahebkar A, Serban MC, Mikhailidis DP, Toth PP, Muntner P, Ursoniu S, et al. Head-to-head comparison of statins versus fibrates in reducing plasma fibrinogen concentrations: A systematic review and meta-analysis. Pharmacological research. 2016;103:236-52.

28. Duval S, Tweedie R. Trim and fill: A simple funnel-plot-based method of testing and adjusting for publication bias in meta-analysis. Biometrics. 2000;56(2):455-63.

29. Borenstein M, Hedges L, Higgins J, Rothstein H. Comprehensive Metaanalysis (Vers. 2). Englewood Cliffs, NJ: Biostat. Inc; 2005.

30. Bycroft C, Freeman C, Petkova D, Band G, Elliott LT, Sharp K, et al. The UK Biobank resource with deep phenotyping and genomic data. Nature. 2018;562(7726):203-9.

31. Dashti HS, Jones SE, Wood AR, Lane JM, van Hees VT, Wang H, et al. Genome-wide association study identifies genetic loci for self-reported habitual sleep duration supported by accelerometerderived estimates. Nature communications. 2019;10(1):1100.

32. Jones SE, van Hees VT, Mazzotti DR, Marques-Vidal P, Sabia S, van der Spek A, et al. Genetic studies of accelerometer-based sleep measures yield new insights into human sleep behaviour. Nature communications. 2019;10(1):1585.

33. Malik R, Chauhan G, Traylor M, Sargurupremraj M, Okada Y, Mishra A, et al. Multiancestry genome-wide association study of 520,000 subjects identifies 32 loci associated with stroke and stroke subtypes. Nat Genet. 2018;50(4):524-37.

34. Adams HP, Jr., Bendixen BH, Kappelle L, Biller J, Love BB, Gordon DL, et al. Classification of subtype of acute ischemic stroke. Definitions for use in a multicenter clinical trial. TOAST. Trial of Org 10172 in Acute Stroke Treatment. Stroke. 1993;24(1):35-41.

35. Bowden J, Davey Smith G, Haycock PC, Burgess S. Consistent Estimation in Mendelian Randomization with Some Invalid Instruments Using a Weighted Median Estimator. Genet Epidemiol. 2016;40(4):304-14.

36. Bowden J, Davey Smith G, Burgess S. Mendelian randomization with invalid instruments: effect estimation and bias detection through Egger regression. Int J Epidemiol. 2015;44(2):512-25. 
37. Burgess S, Bowden J, Fall T, Ingelsson E, Thompson SG. Sensitivity Analyses for Robust Causal Inference from Mendelian Randomization Analyses with Multiple Genetic Variants. Epidemiology. 2017;28(1):30-42.

38. Bowden J, Del Greco MF, Minelli C, Davey Smith G, Sheehan N, Thompson J. A framework for the investigation of pleiotropy in two-sample summary data Mendelian randomization. Statistics in medicine. 2017;36(11):1783-802.

39. Verbanck M, Chen CY, Neale B, Do R. Detection of widespread horizontal pleiotropy in causal relationships inferred from Mendelian randomization between complex traits and diseases. Nat Genet. 2018;50(5):693-8.

40. Song $Q$, Liu X, Zhou W, Wang L, Zheng X, Wang X, et al. Long sleep duration and risk of ischemic stroke and hemorrhagic stroke: the Kailuan Prospective Study. Scientific reports. 2016;6:33664.

41. Petrov MER, Letter AJ, Howard VJ, Kleindorfer D. Self-reported sleep duration in relation to incident stroke symptoms: nuances by body mass and race from the REGARDS study. Journal of Stroke and Cerebrovascular Diseases. 2014;23(2):e123-e32.

42. Leng Y, Cappuccio FP, Wainwright NW, Surtees PG, Luben R, Brayne C, et al. Sleep duration and risk of fatal and nonfatal stroke: a prospective study and meta-analysis. Neurology. 2015;84(11):1072-9.

43. Amagai Y, Ishikawa S, Gotoh T, Kayaba K, Nakamura Y, Kajii E. Sleep duration and incidence of cardiovascular events in a Japanese population: the Jichi Medical School cohort study. Journal of epidemiology. 2010:0912090122-.

44. Helbig AK, StöckI D, Heier M, Ladwig K-H, Meisinger C. Symptoms of insomnia and sleep duration and their association with incident strokes: findings from the population-based MONICA/KORA Augsburg Cohort Study. PLoS One. 2015;10(7):e0134480.

45. Von Ruesten A, Weikert C, Fietze I, Boeing H. Association of sleep duration with chronic diseases in the European Prospective Investigation into Cancer and Nutrition (EPIC)-Potsdam study. PloS one. 2012;7(1):e30972.

46. Magee CA, Kritharides L, Attia J, McElduff P, Banks E. Short and long sleep duration are associated with prevalent cardiovascular disease in Australian adults. Journal of sleep research. 2012;21(4):441-7.

47. Tu X, Cai H, Gao Y-T, Wu X, Ji B-T, Yang G, et al. Sleep duration and its correlates in middle-aged and elderly Chinese women: the Shanghai Women's Health Study. Sleep medicine. 2012;13(9):1138-45.

48. Westerlund A, Bellocco R, Sundström J, Adami H-O, Åkerstedt T, Lagerros YT. Sleep characteristics and cardiovascular events in a large Swedish cohort. European journal of epidemiology. 2013;28(6):463-73.

49. Meng L, Zheng $Y$, Hui R. The relationship of sleep duration and insomnia to risk of hypertension incidence: a meta-analysis of prospective cohort studies. Hypertension Research. 2013;36(11):985.

50. Palomäki $H$, Berg $A$, Meririnne $E$, Kaste $M$, Lönnqvist $R$, Lehtihalmes $M$, et al. Complaints of poststroke insomnia and its treatment with mianserin. Cerebrovascular Diseases. 2003;15(1-2):56-62.

51. Stone KL, Ewing SK, Ancoli-Israel S, Ensrud KE, Redline S, Bauer DC, et al. Self-reported sleep and nap habits and risk of mortality in a large cohort of older women. Journal of the American Geriatrics Society. 2009;57(4):604-11.

52. Cappuccio FP, D'Elia L, Strazzullo P, Miller MA. Quantity and quality of sleep and incidence of type 2 diabetes: a systematic review and meta-analysis. Diabetes care. 2010;33(2):414-20.

53. Spiegal K, Tasali E, Penev P, Van Cauter E. Sleep curtailment in healthy young men is associated with decreased leptin levels, elevated ghrelin levels and increased hunger and appetite. Ann Int Med. 2004;141(11):846-50.

54. Tsubono Y, Fukao A, Hisamichi S. Health practices and mortality in a rural Japanese population. The Tohoku journal of experimental medicine. 1993;171(4):339-48. 
55. Copinschi G. Metabolic and endocrine effects of sleep deprivation. Essential psychopharmacology. 2005;6(6):341-7.

56. Nakajima H, Kaneita Y, Yokoyama E, Harano S, Tamaki T, Ibuka E, et al. Association between sleep duration and hemoglobin A1c level. Sleep medicine. 2008;9(7):745-52.

57. BJORVATN B, Sagen IM, ØYANE N, Waage S, Fetveit A, PALLESEN S, et al. The association between sleep duration, body mass index and metabolic measures in the Hordaland Health Study. Journal of sleep research. 2007;16(1):66-76.

58. Duss SB, Seiler A, Schmidt MH, Pace M, Adamantidis A, Muri RM, et al. The role of sleep in recovery following ischemic stroke: A review of human and animal data. Neurobiology of sleep and circadian rhythms. 2017;2:94-105.

59. Stranges S, Dorn JM, Shipley MJ, Kandala N-B, Trevisan M, Miller MA, et al. Correlates of short and long sleep duration: a cross-cultural comparison between the United Kingdom and the United States: the Whitehall II Study and the Western New York Health Study. American journal of epidemiology. 2008;168(12):1353-64.

60. Krueger PM, Friedman EM. Sleep duration in the United States: a cross-sectional populationbased study. American journal of epidemiology. 2009;169(9):1052-63.

61. Patel SR, Malhotra A, Gottlieb DJ, White DP, Hu FB. Correlates of long sleep duration. Sleep. 2006;29(7):881-9.

62. Sterr A, Kuhn M, Nissen C, Ettine D, Funk S, Feige B, et al. Post-stroke insomnia in communitydwelling patients with chronic motor stroke: physiological evidence and implications for stroke care. Scientific reports. 2018;8(1):8409.

63. Wu M-P, Lin H-J, Weng S-F, Ho C-H, Wang J-J, Hsu Y-W. Insomnia subtypes and the subsequent risks of stroke: report from a nationally representative cohort. Stroke. 2014;45(5):1349-54. 
Table 1. Characteristics of the Prospective Cohort Studies included in the meta-analysis.

\begin{tabular}{|c|c|c|c|c|c|c|}
\hline $\begin{array}{l}\text { Author, year } \\
\text { and References }\end{array}$ & $\begin{array}{l}\text { Country, } \\
\text { region/cohort }\end{array}$ & $\begin{array}{l}\text { Men } \\
\text { (\%) }\end{array}$ & $\begin{array}{l}\text { Mean } \\
\text { Age }\end{array}$ & $\begin{array}{l}\text { follow-up } \\
\text { time } \\
\text { (Years) }\end{array}$ & $\begin{array}{l}\text { Assessment of sleep } \\
\text { duration }\end{array}$ & Main confounders \\
\hline Chen, 2008 (1) & $\begin{array}{l}\text { Prospective cohort study, } \\
\text { USA }\end{array}$ & 0 & unclear & 7.5 & Interview questioning & $\begin{array}{l}\text { Age, race, education, family income, } \\
\text { employment status, depression, smoking, } \\
\text { exercise, use of hormone therapy, prior } \\
\text { cardiovascular disease, diabetes mellitus, } \\
\text { hypertension, high cholesterol level } \\
\text { requiring pills and body mass index. }\end{array}$ \\
\hline $\begin{array}{l}\text { Hamazaki, } 2011 \\
\text { (2) }\end{array}$ & $\begin{array}{l}\text { Prospective cohort study, } \\
\text { Japan }\end{array}$ & 100 & 44 & 14 & $\begin{array}{l}\text { Self-administered } \\
\text { questionnaire }\end{array}$ & $\begin{array}{l}\text { Age, type of job, working hours, mental } \\
\text { workload, body mass index, mean blood } \\
\text { pressure, HbA1c, total cholesterol, current } \\
\text { smoking habit, drinking habit, leisure-time } \\
\text { physical activity, medication for } \\
\text { hypertension, diabetes, } \\
\text { hypercholesterolemia }\end{array}$ \\
\hline Helbig, 2015 (3) & $\begin{array}{l}\text { Prospective cohort study, } \\
\text { Germany }\end{array}$ & 50 & 48 & 14 & Interview questioning & $\begin{array}{l}\text { Age, survey, education, physical activity, } \\
\text { alcohol consumption, current smoking } \\
\text { activity, body mass index, hypertension, } \\
\text { diabetes and dyslipidemia }\end{array}$ \\
\hline Leng, 2015 (4) & $\begin{array}{l}\text { Prospective cohort study, } \\
\text { UK }\end{array}$ & 46 & 62 & 9.5 & Questionnaire & $\begin{array}{l}\text { Age, sex, social class, education, marital } \\
\text { status, smoking, alcohol intake, hypnotic } \\
\text { drug use, family history of stroke, body } \\
\text { mass index, physical activity, depression, } \\
\text { systolic blood pressure, diastolic blood } \\
\text { pressure, preexisting diabetes, myocardial } \\
\text { infarction, cholesterol level and } \\
\text { hypertension drug use. }\end{array}$ \\
\hline
\end{tabular}




\begin{tabular}{|c|c|c|c|c|c|c|}
\hline Magee, 2011 (5) & $\begin{array}{l}\text { Prospective cohort study, } \\
\text { Australia }\end{array}$ & 47 & 63 & unclear & $\begin{array}{l}\text { Self-reported } \\
\text { questionnaire }\end{array}$ & $\begin{array}{l}\text { Age, sex, country of birth, marital status, } \\
\text { education, employment status, } \\
\text { remoteness, body mass index, physical } \\
\text { activity, smoking, alcohol and screen time. }\end{array}$ \\
\hline Qureshi, 1997 (6) & $\begin{array}{l}\text { Prospective cohort study, } \\
\text { USA }\end{array}$ & 36 & unclear & 10 & $\begin{array}{l}\text { Participants were } \\
\text { interviewed }\end{array}$ & $\begin{array}{l}\text { Age, sex, race, education, cigarette } \\
\text { smoking, systolic blood pressure, serum } \\
\text { cholesterol level, diabetes and body mass } \\
\text { index. }\end{array}$ \\
\hline $\begin{array}{l}\text { Ruiter Petrov, } \\
\text { (7) } 2014\end{array}$ & $\begin{array}{l}\text { Prospective cohort study, } \\
\text { USA }\end{array}$ & 44 & 61 & 2 & $\begin{array}{l}\text { Participants were } \\
\text { questioned on sleep }\end{array}$ & $\begin{array}{l}\text { Demographics, stroke risk factors, } \\
\text { psychological symptoms, health behaviors } \\
\text { and diet quality. }\end{array}$ \\
\hline Song, 2016 (8) & $\begin{array}{l}\text { Prospective cohort study, } \\
\text { China }\end{array}$ & 79 & 51 & 7.9 & $\begin{array}{l}\text { Interviews, death } \\
\text { certificates, discharge } \\
\text { summaries and medical } \\
\text { records }\end{array}$ & $\begin{array}{l}\text { Age, sex, marital status, income, education } \\
\text { level, smoking status, physical activity, } \\
\text { family history of stroke, body mass index, } \\
\text { blood pressure, blood glucose, total } \\
\text { cholesterol, lipid-lowering drug use, } \\
\text { hypoglycemic drug use, history of } \\
\text { myocardial infarction, snoring status, C- } \\
\text { reactive protein and atrial fibrillation. }\end{array}$ \\
\hline Tu, 2012 (9) & $\begin{array}{l}\text { Prospective cohort study, } \\
\text { China }\end{array}$ & 0 & 60 & 4 & $\begin{array}{l}\text { Participants were } \\
\text { questioned on sleep }\end{array}$ & $\begin{array}{l}\text { Age, education level, occupational status, } \\
\text { night-shift work, annual income, } \\
\text { menopausal status, marital status, number } \\
\text { of live births, physical activity, passive } \\
\text { smoking tea consumption, energy intake, } \\
\text { time spend watching TV and vitamin } \\
\text { supplement use. }\end{array}$ \\
\hline $\begin{array}{l}\text { Von Ruesten, } \\
2012(10)\end{array}$ & $\begin{array}{l}\text { Prospective cohort study, } \\
\text { Germany }\end{array}$ & 39 & 49 & 8 & $\begin{array}{l}\text { Participants were } \\
\text { interviewed about their } \\
\text { sleep }\end{array}$ & $\begin{array}{l}\text { Age, sex, sleeping disorders, alcohol intake, } \\
\text { smoking status, walking cycling sports, } \\
\text { employment status, education, body mass } \\
\text { index, waist-to-hip ratio, hypertension, high } \\
\text { blood lipid, caffeinated beverages, }\end{array}$ \\
\hline
\end{tabular}




\begin{tabular}{|l|l|l|l|l|l|l|}
\hline & & & & & & $\begin{array}{l}\text { satisfaction with life, satisfaction with } \\
\text { health and intake of antidepressants }\end{array}$ \\
\hline $\begin{array}{l}\text { Amagai, 2010 } \\
(11)\end{array}$ & $\begin{array}{l}\text { Prospective cohort study, } \\
\text { Japan }\end{array}$ & 39 & 55 & 10.7 & $\begin{array}{l}\text { Interview for sleep } \\
\text { duration }\end{array}$ & $\begin{array}{l}\text { Age, systolic blood pressure, total } \\
\text { cholesterol, body mass index, smoking } \\
\text { habits and alcohol drinking habits }\end{array}$ \\
\hline $\begin{array}{l}\text { Westerlund, } \\
2013(12)\end{array}$ & $\begin{array}{l}\text { Prospective cohort study, } \\
\text { Sweden }\end{array}$ & 35 & unclear & 13 & Questionnaire & $\begin{array}{l}\text { Age, sex, education, employment status, } \\
\text { smoking, alcohol, snoring, work schedule, } \\
\text { depressive symptoms, self-rated health, } \\
\text { physical activity, body mass index, } \\
\text { diabetes, lipid disturbance and } \\
\text { hypertension. }\end{array}$ \\
\hline
\end{tabular}




\section{References:}

1. Chen J-C, Brunner RL, Ren H, Wassertheil-Smoller S, Larson JC, Levine DW, et al. Sleep duration and risk of ischemic stroke in postmenopausal women. Stroke; a journal of cerebral circulation. 2008;39(12):3185.

2. Hamazaki Y, Morikawa Y, Nakamura K, Sakurai M, Miura K, Ishizaki M, et al. The effects of sleep duration on the incidence of cardiovascular events among middle-aged male workers in Japan. Scandinavian journal of work, environment \& health. 2011:411-7.

3. Helbig AK, StöckI D, Heier M, Ladwig K-H, Meisinger C. Symptoms of insomnia and sleep duration and their association with incident strokes: findings from the population-based MONICA/KORA Augsburg Cohort Study. PLoS One. 2015;10(7):e0134480.

4. Leng Y, Cappuccio FP, Wainwright NW, Surtees PG, Luben R, Brayne C, et al. Sleep duration and risk of fatal and nonfatal stroke: a prospective study and meta-analysis. Neurology. 2015;84(11):1072-9.

5. Magee CA, Kritharides L, Attia J, McElduff P, Banks E. Short and long sleep duration are associated with prevalent cardiovascular disease in Australian adults. Journal of sleep research. 2012;21(4):441-7.

6. Qureshi Al, Giles WH, Croft JB, Bliwise DL. Habitual sleep patterns and risk for stroke and coronary heart disease: a 10 - year follow - up from NHANES I. Neurology. 1997;48(4):904-10.

7. Petrov MER, Letter AJ, Howard VJ, Kleindorfer D. Self-reported sleep duration in relation to incident stroke symptoms: nuances by body mass and race from the REGARDS study. Journal of Stroke and Cerebrovascular Diseases. 2014;23(2):e123-e32.

8. Song $Q$, Liu X, Zhou W, Wang L, Zheng X, Wang X, et al. Long sleep duration and risk of ischemic stroke and hemorrhagic stroke: the Kailuan Prospective Study. Scientific reports. 2016;6:33664.

9. Tu X, Cai H, Gao Y-T, Wu X, Ji B-T, Yang G, et al. Sleep duration and its correlates in middle-aged and elderly Chinese women: the Shanghai Women's Health Study. Sleep medicine. 2012;13(9):1138-45.

10. Von Ruesten A, Weikert C, Fietze I, Boeing H. Association of sleep duration with chronic diseases in the European Prospective Investigation into Cancer and Nutrition (EPIC)-Potsdam study. PloS one. 2012;7(1):e30972.

11. Amagai Y, Ishikawa S, Gotoh T, Kayaba K, Nakamura Y, Kajii E. Sleep duration and incidence of cardiovascular events in a Japanese population: the Jichi Medical School cohort study. Journal of epidemiology. 2010:0912090122-.

12. Westerlund A, Bellocco R, Sundström J, Adami H-O, Åkerstedt T, Lagerros YT. Sleep characteristics and cardiovascular events in a large Swedish cohort. European journal of epidemiology. 2013;28(6):463-73. 


\begin{tabular}{|c|c|c|c|c|c|c|c|c|c|c|c|}
\hline \multirow[t]{2}{*}{ Exposures } & & \multicolumn{4}{|c|}{ MR } & \multicolumn{3}{|c|}{ Heterogeneity } & \multicolumn{3}{|c|}{ Pleiotropy } \\
\hline & & Method & beta & SE & $\mathbf{p}$ & Method & $\mathbf{Q}$ & $p$ & Intercept & SE & $p$ \\
\hline \multirow{16}{*}{$\begin{array}{l}\text { sleep } \\
\text { duration } \\
\text { (self- } \\
\text { reported) }\end{array}$} & \multirow[t]{4}{*}{ IS } & MR Egger & -0.229 & 0.341 & 0.504 & \multirow[t]{2}{*}{ MR Egger } & \multirow[t]{2}{*}{48.668} & \multirow[t]{2}{*}{0.445} & \multirow[t]{4}{*}{0.0034} & \multirow[t]{4}{*}{0.0057} & \multirow[t]{4}{*}{0.547} \\
\hline & & WM & -0.019 & 0.154 & 0.901 & & & & & & \\
\hline & & IVW & -0.031 & 0.098 & 0.747 & \multirow[t]{2}{*}{ IVW } & \multirow[t]{2}{*}{49.040} & \multirow[t]{2}{*}{0.471} & & & \\
\hline & & RAPS & 0.004 & 0.103 & 0.967 & & & & & & \\
\hline & \multirow[t]{4}{*}{ CES } & MR Egger & 0.537 & 0.725 & 0.462 & \multirow[t]{2}{*}{ MR Egger } & \multirow[t]{2}{*}{58.130} & \multirow[t]{2}{*}{0.150} & \multirow[t]{4}{*}{-0.010} & \multirow[t]{4}{*}{0.012} & \multirow[t]{4}{*}{0.409} \\
\hline & & WM & 0.163 & 0.287 & 0.569 & & & & & & \\
\hline & & IVW & -0.039 & 0.208 & 0.849 & \multirow[t]{2}{*}{ IVW } & \multirow[t]{2}{*}{58.967} & \multirow[t]{2}{*}{0.155} & & & \\
\hline & & RAPS & 0.055 & 0.216 & 0.796 & & & & & & \\
\hline & \multirow[t]{4}{*}{ LAS } & MR Egger & -0.658 & 0.878 & 0.457 & \multirow[t]{2}{*}{ MR Egger } & \multirow[t]{2}{*}{51.42584} & \multirow{2}{*}{0.341} & \multirow[t]{4}{*}{0.0072} & \multirow[t]{4}{*}{0.014} & \multirow[t]{4}{*}{0.626} \\
\hline & & WM & -0.131 & 0.382 & 0.731 & & & & & & \\
\hline & & IVW & -0.246 & 0.251 & 0.328 & \multirow[t]{2}{*}{ IVW } & \multirow[t]{2}{*}{51.68298} & 0.369 & & & \\
\hline & & RAPS & -0.249 & 0.259 & 0.336 & & & & & & \\
\hline & SVS & MR Egger & -0.369 & 0.832 & 0.658 & MR Egger & 53.354 & 0.275 & 0.0046 & 0.013 & 0.738 \\
\hline & & WM & -0.175 & 0.367 & 0.634 & & & & & & \\
\hline & & IVW & -0.102 & 0.238 & 0.667 & IVW & 53.479 & 0.306 & & & \\
\hline & & RAPS & -0.159 & 0.258 & 0.536 & & & & & & \\
\hline
\end{tabular}

Weighted median: WM, Inverse variance weighted: IVW, SE: standard error, beta: beta-coefficients, RAPS: MR-Robust Adjusted Profile Score, MR:

Mendelian randomization, IS: ischemic stroke, CES: cardioembolic stroke, LAS: large artery stroke, SVS: small vessel stroke 


\begin{tabular}{|c|c|c|c|c|c|c|c|c|c|c|c|}
\hline \multirow{2}{*}{\multicolumn{2}{|c|}{ Exposures }} & \multicolumn{4}{|c|}{ MR } & \multicolumn{3}{|c|}{ Heterogeneity } & \multicolumn{3}{|c|}{ Pleiotropy } \\
\hline & & Method & beta & SE & $\mathbf{p}$ & Method & $\mathbf{Q}$ & $\mathbf{p}$ & Intercept & SE & $p$ \\
\hline \multirow{16}{*}{$\begin{array}{l}\text { sleep } \\
\text { duration } \\
\text { (accelero } \\
\text { meter } \\
\text { derived) }\end{array}$} & \multirow[t]{4}{*}{ IS } & MR Egger & -0.043 & 0.261 & 0.874 & \multirow[t]{2}{*}{ MR Egger } & \multirow[t]{2}{*}{3.344} & \multirow[t]{2}{*}{0.764} & \multirow[t]{4}{*}{0.0037} & \multirow[t]{4}{*}{0.011} & \multirow[t]{4}{*}{0.759} \\
\hline & & WM & -0.006 & 0.132 & 0.963 & & & & & & \\
\hline & & IVW & 0.033 & 0.102 & 0.739 & \multirow[t]{2}{*}{ IVW } & \multirow[t]{2}{*}{3.446} & \multirow[t]{2}{*}{0.840} & & & \\
\hline & & RAPS & 0.034 & 0.105 & 0.746 & & & & & & \\
\hline & \multirow[t]{4}{*}{ CES } & MR Egger & 0.233 & 0.523 & 0.671 & \multirow[t]{2}{*}{ MR Egger } & \multirow[t]{2}{*}{2.190} & \multirow[t]{2}{*}{0.901} & \multirow[t]{4}{*}{-0.014} & \multirow[t]{4}{*}{0.023} & \multirow[t]{4}{*}{0.550} \\
\hline & & WM & -0.039 & 0.256 & 0.878 & & & & & & \\
\hline & & IVW & -0.072 & 0.198 & 0.713 & \multirow[t]{2}{*}{ IVW } & \multirow[t]{2}{*}{2.590} & \multirow[t]{2}{*}{0.920} & & & \\
\hline & & RAPS & -0.073 & 0.205 & 0.720 & & & & & & \\
\hline & \multirow[t]{4}{*}{ LAS } & MR Egger & -0.351 & 0.683 & 0.625 & \multirow[t]{2}{*}{ MR Egger } & \multirow[t]{2}{*}{6.404} & \multirow{2}{*}{0.379} & \multirow[t]{4}{*}{0.0223} & \multirow[t]{4}{*}{0.030} & \multirow[t]{4}{*}{0.492} \\
\hline & & WM & -0.132 & 0.336 & 0.693 & & & & & & \\
\hline & & IVW & 0.109 & 0.253 & 0.664 & \multirow[t]{2}{*}{ IVW } & \multirow[t]{2}{*}{6.975} & 0.431 & & & \\
\hline & & RAPS & 0.056 & 0.273 & 0.835 & & & & & & \\
\hline & SVS & MR Egger & 0.038 & 0.720 & 0.959 & MR Egger & 7.557 & 0.272 & 0.0157 & 0.031 & 0.639 \\
\hline & & WM & 0.252 & 0.320 & 0.430 & & & & & & \\
\hline & & IVW & 0.367 & 0.254 & 0.149 & IVW & 7.863 & 0.344 & & & \\
\hline & & RAPS & 0.353 & 0.266 & 0.185 & & & & & & \\
\hline
\end{tabular}

Weighted median: WM, Inverse variance weighted: IVW, SE: standard error, beta: beta-coefficients, RAPS: MR-Robust Adjusted Profile Score, MR: Mendelian randomization, IS: ischemic stroke, CES: cardioembolic stroke, LAS: large artery stroke, SVS: small vessel stroke 


\begin{tabular}{|c|c|c|c|c|c|c|c|c|c|c|c|}
\hline \multirow[t]{2}{*}{ Exposures } & \multirow[t]{2}{*}{ 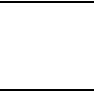 } & \multicolumn{4}{|c|}{ MR } & \multicolumn{3}{|c|}{ Heterogeneity } & \multicolumn{3}{|c|}{ Pleiotropy } \\
\hline & & Method & beta & SE & $\mathbf{p}$ & Method & $\mathbf{Q}$ & $\mathbf{p}$ & Intercept & SE & $\mathbf{p}$ \\
\hline \multirow{16}{*}{$\begin{array}{l}\text { Short } \\
\text { sleep } \\
\text { duration }\end{array}$} & \multirow[t]{4}{*}{ IS } & MR Egger & 1.123 & 1.70 & 0.515 & \multirow[t]{2}{*}{ MR Egger } & \multirow[t]{2}{*}{15.057} & \multirow[t]{2}{*}{0.820} & \multirow[t]{4}{*}{-0.0053} & \multirow[t]{4}{*}{0.0114} & \multirow[t]{4}{*}{0.643} \\
\hline & & WM & 0.261 & 0.461 & 0.571 & & & & & & \\
\hline & & IVW & 0.343 & 0.356 & 0.335 & \multirow[t]{2}{*}{ IVW } & \multirow[t]{2}{*}{15.278} & \multirow[t]{2}{*}{0.850} & & & \\
\hline & & RAPS & 0.323 & 0.373 & 0.386 & & & & & & \\
\hline & \multirow[t]{4}{*}{ CES } & MR Egger & 2.089 & 3.732 & 0.581 & \multirow[t]{2}{*}{ MR Egger } & \multirow[t]{2}{*}{26.571} & \multirow[t]{2}{*}{0.185} & \multirow[t]{4}{*}{-0.0169} & \multirow[t]{4}{*}{0.0250} & \multirow[t]{4}{*}{0.505} \\
\hline & & WM & -1.590 & 0.986 & 0.106 & & & & & & \\
\hline & & IVW & -0.384 & 0.763 & 0.614 & \multirow[t]{2}{*}{ IVW } & \multirow{2}{*}{27.152} & \multirow[t]{2}{*}{0.205} & & & \\
\hline & & RAPS & -0.755 & 0.764 & 0.322 & & & & & & \\
\hline & \multirow[t]{4}{*}{ LAS } & MR Egger & 2.098 & 4.559 & 0.650 & \multirow[t]{2}{*}{ MR Egger } & \multirow[t]{2}{*}{24.291} & \multirow[t]{2}{*}{0.2791} & \multirow[t]{4}{*}{-0.0053} & \multirow[t]{4}{*}{0.0307} & \multirow[t]{4}{*}{0.863} \\
\hline & & WM & 1.583 & 1.191 & 0.183 & & & & & & \\
\hline & & IVW & 1.321 & 0.932 & 0.156 & \multirow[t]{2}{*}{ IVW } & 24.327 & 0.3303 & & & \\
\hline & & RAPS & 1.437 & 0.935 & 0.124 & & & & & & \\
\hline & SVS & MR Egger & -0.047 & 3.901 & 0.990 & MR Egger & 21.220 & 0.445 & 0.00026 & 0.0263 & 0.992 \\
\hline & & WM & -0.004 & 1.098 & 0.996 & & & & & & \\
\hline & & IVW & -0.009 & 0.822 & 0.990 & IVW & 21.220 & 0.507 & & & \\
\hline & & RAPS & -0.136 & 0.865 & 0.875 & & & & & & \\
\hline
\end{tabular}

Weighted median: WM, Inverse variance weighted: IVW, SE: standard error, beta: beta-coefficients, RAPS: MR-Robust Adjusted Profile Score, MR:

Mendelian randomization, IS: ischemic stroke, CES: cardioembolic stroke, LAS: large artery stroke, SVS: small vessel stroke 


\begin{tabular}{|c|c|c|c|c|c|c|c|c|c|c|c|}
\hline \multirow[t]{2}{*}{ Exposures } & & \multicolumn{4}{|c|}{ MR } & \multicolumn{3}{|c|}{ Heterogeneity } & \multicolumn{3}{|c|}{ Pleiotropy } \\
\hline & & Method & beta & SE & $\mathbf{p}$ & Method & $\mathbf{Q}$ & $\mathbf{p}$ & Intercept & SE & $p$ \\
\hline \multirow{16}{*}{$\begin{array}{l}\text { Long } \\
\text { sleep } \\
\text { duration }\end{array}$} & \multirow[t]{4}{*}{ IS } & MR Egger & 1.836 & 2.531 & 0.495 & \multirow[t]{2}{*}{ MR Egger } & \multirow[t]{2}{*}{2.311} & \multirow[t]{2}{*}{0.888} & \multirow[t]{4}{*}{-0.012} & \multirow[t]{4}{*}{0.0139} & \multirow[t]{4}{*}{0.418} \\
\hline & & WM & -0.132 & 1.096 & 0.903 & & & & & & \\
\hline & & IVW & -0.219 & 0.891 & 0.805 & \multirow[t]{2}{*}{ IVW } & \multirow[t]{2}{*}{3.064} & \multirow[t]{2}{*}{0.878} & & & \\
\hline & & RAPS & -0.222 & 0.929 & 0.810 & & & & & & \\
\hline & \multirow[t]{4}{*}{ CES } & MR Egger & -3.836 & 5.247 & 0.492 & \multirow[t]{2}{*}{ MR Egger } & \multirow[t]{2}{*}{4.742} & \multirow[t]{2}{*}{0.577} & \multirow[t]{4}{*}{0.0328} & \multirow[t]{4}{*}{0.0283} & \multirow[t]{4}{*}{0.290} \\
\hline & & WM & 2.074 & 2.229 & 0.352 & & & & & & \\
\hline & & IVW & 1.895 & 1.751 & 0.279 & \multirow[t]{2}{*}{ IVW } & \multirow{2}{*}{6.085} & \multirow{2}{*}{0.529} & & & \\
\hline & & RAPS & 2.396 & 1.845 & 0.194 & & & & & & \\
\hline & \multirow[t]{4}{*}{ LAS } & MR Egger & 16.35 & 6.517 & 0.045 & \multirow[t]{2}{*}{ MR Egger } & \multirow[t]{2}{*}{3.113} & \multirow[t]{2}{*}{0.794} & \multirow[t]{4}{*}{-0.0823} & \multirow[t]{4}{*}{0.0355} & \multirow[t]{4}{*}{0.059} \\
\hline & & WM & 3.095 & 2.898 & 0.285 & & & & & & \\
\hline & & IVW & 2.126 & 2.472 & 0.389 & \multirow[t]{2}{*}{ IVW } & \multirow[t]{2}{*}{8.521} & 0.288 & & & \\
\hline & & RAPS & 3.084 & 2.702 & 0.253 & & & & & & \\
\hline & SVS & MR Egger & 5.993 & 5.924 & 0.350 & MR Egger & 3.877 & 0.693 & -0.027 & 0.0325 & 0.436 \\
\hline & & WM & 1.313 & 2.640 & 0.619 & & & & & & \\
\hline & & IVW & 1.369 & 2.072 & 0.508 & IVW & 4.571 & 0.712 & & & \\
\hline & & RAPS & 1.394 & 2.178 & 0.522 & & & & & & \\
\hline
\end{tabular}

Weighted median: WM, Inverse variance weighted: IVW, SE: standard error, beta: beta-coefficients, RAPS: MR-Robust Adjusted Profile Score, MR:

Mendelian randomization, IS: ischemic stroke, CES: cardioembolic stroke, LAS: large artery stroke, SVS: small vessel stroke 
Supplementary Table 1. MOOSE Reporting Checklist for Authors, Editors, and Reviewers of Meta-analyses of Observational Studies

\begin{tabular}{|c|c|}
\hline Reporting of background should include: & $\begin{array}{l}\text { Page } \\
\text { number: }\end{array}$ \\
\hline $\begin{array}{l}\text { Problem definition } \\
\text { Hypothesis statement } \\
\text { Description of study outcome(s) } \\
\text { Type of exposure or intervention used } \\
\text { Type of study designs used } \\
\text { Study population }\end{array}$ & $\begin{array}{l}5 \\
5 \\
5 \\
5 \\
5 \\
5\end{array}$ \\
\hline Reporting of search strategy should include: & $\begin{array}{l}\text { Page } \\
\text { number: }\end{array}$ \\
\hline $\begin{array}{l}\text { Qualifications of searchers (eg, librarians and investigators) } \\
\text { Search strategy, including time period included in the synthesis and keywords Effort } \\
\text { to include all available studies, including contact with authors Databases and } \\
\text { registries searched } \\
\text { Search software used, name and version, including special features used (eg, explosion) Use of } \\
\text { hand searching (eg, reference lists of obtained articles) } \\
\text { List of citations located and those excluded, including justification Method of } \\
\text { addressing articles published in languages other than English Method of } \\
\text { handling abstracts and unpublished studies } \\
\text { Description of any contact with authors }\end{array}$ & $\begin{array}{l}1 \\
\text { Appendix } 1 \\
6-7 \\
6-7 \\
6-7 \\
6-7 \\
\text { Figure 1 } \\
- \\
6-7 \\
-\end{array}$ \\
\hline Reporting of methods should include: & $\begin{array}{l}\text { Page } \\
\text { number: }\end{array}$ \\
\hline
\end{tabular}




\begin{tabular}{|c|c|}
\hline $\begin{array}{l}\text { Description of relevance or appropriateness of studies assembled for assessing the hypothesis to be } \\
\text { tested }\end{array}$ & $6-7$ \\
\hline Rationale for the selection and coding of data (eg, sound clinical principles or convenience) & $6-7$ \\
\hline Documentation of how data were classified and coded (eg, multiple raters, blinding, and interrater reliability) & $6-7$ \\
\hline $\begin{array}{l}\text { Assessment of study quality, including blinding of quality assessors; stratification or regression on possible predictors of study } \\
\text { results }\end{array}$ & 6-7 \\
\hline Assessment of heterogeneity & $6-7$ \\
\hline Provision of appropriate tables and graphics & $\begin{array}{l}\text { Tables and } \\
\text { Figures }\end{array}$ \\
\hline Reporting of results should include: & $\begin{array}{l}\text { Page } \\
\text { number: }\end{array}$ \\
\hline $\begin{array}{l}\text { Graphic summarizing individual study estimates and overall estimate Table } \\
\text { giving descriptive information for each study included } \\
\text { Results of sensitivity testing (eg, subgroup analysis) } \\
\text { Indication of statistical uncertainty of findings }\end{array}$ & $\begin{array}{l}\text { Figures } \\
\text { Table } \\
8-12 \\
8-12\end{array}$ \\
\hline Reporting of discussion should include: & $\begin{array}{l}\text { Page } \\
\text { number: }\end{array}$ \\
\hline $\begin{array}{l}\text { Quantitative assessment of bias (eg, publication bias) } \\
\text { Justification for exclusion (eg, exclusion of non-English-language citations) } \\
\text { Assessment of quality of included studies }\end{array}$ & $\begin{array}{l}13-16 \\
- \\
13-16\end{array}$ \\
\hline Reporting of conclusions should include: & $\begin{array}{l}\text { Page } \\
\text { number: }\end{array}$ \\
\hline $\begin{array}{l}\text { Consideration of alternative explanations for observed results } \\
\text { Generalization of the conclusions (ie, appropriate for the data presented and within the domain of the } \\
\text { literature review) } \\
\text { Guidelines for future research } \\
\text { Disclosure of funding source }\end{array}$ & $\begin{array}{l}16-17 \\
16-17 \\
- \\
17\end{array}$ \\
\hline
\end{tabular}




\begin{tabular}{|c|c|c|}
\hline No & Concept & Search terms \\
\hline 1 & Stroke & $\begin{array}{l}\text { cerebrovascular[tiab] OR stroke[tiab] OR TIA[tiab] OR transient } \\
\text { ischemic*[tiab] OR CVA[tiab] OR cerebral infarction[tiab] OR } \\
\text { Cerebrovascular accident [Mesh:NoExp] OR stroke[Mesh:NoExp] }\end{array}$ \\
\hline 2 & Sleep duration & sleep duration [tiab] \\
\hline 3 & $\begin{array}{l}\text { Combination Exposure And } \\
\text { Outcome }\end{array}$ & \#1 AND \#2 \\
\hline 4 & Limit & $\begin{array}{l}\text { Rats[Mesh:NoExp]) OR Mice[Mesh:NoExp]) OR rat[Title/Abstract]) OR } \\
\text { rats[Title/Abstract]) OR mouse[Title/Abstract]) OR mice[Title/Abstract]) OR } \\
\text { vivo[Title/Abstract]) OR vitro[Title/Abstract]) }\end{array}$ \\
\hline 5 & Limit & \#3 NOT \#4 \\
\hline
\end{tabular}




\section{NEWCASTLE - OTTAWA QUALITY ASSESSMENT SCALE - COHORT STUDIES}

Note: A study can be awarded a maximum of one star for each numbered item within the Selection and Outcome categories. A maximum of two stars can be given for Comparability.

\section{Selection}

1) Representativeness of the exposed cohort

a) truly representative of the average healthy adults in the community

b) somewhat representative of the average healthy adults in the community

c) selected group of users e.g. nurses, volunteers, vegetarian

d) no description of the derivation of the cohort

2) Selection of the non-exposed cohort

a) drawn from the same community as the exposed cohort $\star$

b) drawn from a different source

c) no description of the derivation of the non-exposed cohort

3) Ascertainment of exposure

a) secure record (e.g. 7 day food diary)

b) structured interview/ $\geq 2$ dietary recalls/diet history/food frequency questionnaire validated for dairy components

c) written self-report (e.g. $<2$ dietary recalls/non-validated food frequency questionnaire or not reported whether food frequency questionnaire was validated)

d) no description

4) Demonstration that outcome of interest was not present at start of study

a) yes $\star$

b) no

\section{Comparability}

1) Comparability of cohorts on the basis of the design or analysis

a) study controls for age, sex, smoking, total energy intake, and body mass index $\star$

b) study controls for any additional factor (e.g. physical activity, alcohol intake, family history of diabetes, dietary factors)

\section{Outcome}

1) Assessment of outcome 
a) independent blind assessment (e.g. clinical diagnosis/complete medical information available). $\star$

b) record linkage/medical record or validated self-report $\star$

c) non-validated self-report

d) no description

2) Was follow-up long enough for outcomes to occur

a) yes/ follow up period for outcome of interest is 10 years or over

b) no

3) Adequacy of follow-up of cohorts

a) complete follow-up - all subjects accounted for

b) subjects lost to follow-up unlikely to introduce bias - small number lost $\leq 20 \%$ follow-up, or description provided of those lost $\star$

c) follow-up rate $<80 \%$ or no description of those lost

d) no statement

Supplemental Table 3. Quality assessment of selected cohorts studies.

\begin{tabular}{|c|c|c|c|c|c|c|c|c|c|}
\hline \multirow[b]{2}{*}{ Studies } & \multicolumn{4}{|c|}{ Selection } & Comparability & \multicolumn{3}{|l|}{ Outcome } & \multirow[b]{2}{*}{$\begin{array}{l}\text { Total } \\
\text { score }\end{array}$} \\
\hline & $\begin{array}{l}\text { Representativeness } \\
\text { of the exposed } \\
\text { cohort }\end{array}$ & $\begin{array}{l}\text { Selection } \\
\text { of the } \\
\text { non- } \\
\text { exposed } \\
\text { cohort }\end{array}$ & $\begin{array}{l}\text { Ascertainment } \\
\text { of exposure }\end{array}$ & $\begin{array}{c}\text { Outcome } \\
\text { not } \\
\text { present } \\
\text { at start } \\
\text { of study }\end{array}$ & $\begin{array}{l}\text { Comparability } \\
\text { of cohorts on } \\
\text { the basis of } \\
\text { the design or } \\
\text { analysis }\end{array}$ & $\begin{array}{l}\text { Assessment } \\
\text { of outcome }\end{array}$ & $\begin{array}{l}\text { Follow- } \\
\text { up long } \\
\text { enough } \\
\text { for } \\
\text { outcomes } \\
\text { to occur }\end{array}$ & $\begin{array}{l}\text { Adequacy } \\
\text { of follow- } \\
\text { up of } \\
\text { cohorts }\end{array}$ & \\
\hline $\begin{array}{l}\text { Chen, } 2008 \\
\text { (1) }\end{array}$ & c & $A \star$ & $B \star$ & $A \star$ & $B \star$ & $B \star$ & B & $B \star$ & 9 \\
\hline $\begin{array}{l}\text { Hamazaki, } \\
2011 \text { (2) }\end{array}$ & C & $A \star$ & $B \star$ & $A \star$ & $A \star$ & $B \star$ & $A \star$ & $B \star$ & 8 \\
\hline $\begin{array}{l}\text { Helbig, } \\
2015 \text { (3) }\end{array}$ & C & $A \star$ & $B \star$ & $A \star$ & $A \star B \star$ & $B \star$ & $A \star$ & $B \star$ & 8 \\
\hline
\end{tabular}




\begin{tabular}{|c|c|c|c|c|c|c|c|c|c|c|}
\hline $\begin{array}{l}\text { Leng, } 2015 \\
\text { (4) }\end{array}$ & C & $A \star$ & $B \star$ & $A \star$ & $A \star$ & $B \star$ & $B \star$ & B & $B \star$ & 9 \\
\hline $\begin{array}{l}\text { Magee, } \\
2011(5)\end{array}$ & C & $A \star$ & $B \star$ & $A \star$ & $A \star$ & $B \star$ & $B \star$ & $A \star$ & $B \star$ & 8 \\
\hline $\begin{array}{l}\text { Qureshi, } \\
1997 \text { (6) }\end{array}$ & C & $A \star$ & $B \star$ & $A \star$ & $A \star$ & $B \star$ & $B \star$ & $A \star$ & $B \star$ & 8 \\
\hline $\begin{array}{l}\text { Ruiter } \\
\text { Petrov, } \\
\text { (7) } 2014\end{array}$ & C & $A \star$ & $B \star$ & $A \star$ & $A \star$ & $B \star$ & $B \star$ & $A \star$ & $B \star$ & 8 \\
\hline $\begin{array}{l}\text { Song, } 2016 \\
\text { (8) }\end{array}$ & $B \star$ & $A \star$ & C & $A \star$ & $A \star$ & $B \star$ & $B \star$ & $A \star$ & C & 7 \\
\hline $\begin{array}{l}\text { Tu, } 2012 \\
\text { (9) }\end{array}$ & C & $A \star$ & $B \star$ & $A \star$ & $A \star$ & $B \star$ & $B \star$ & B & $B \star$ & 9 \\
\hline $\begin{array}{l}\text { Von } \\
\text { Ruesten, } \\
2012 \text { (10) }\end{array}$ & $B \star$ & $A \star$ & C & $A \star$ & $A \star$ & $B \star$ & $B \star$ & $A \star$ & C & 7 \\
\hline $\begin{array}{l}\text { Amagai, } \\
2010 \text { (11) }\end{array}$ & C & $A \star$ & $B \star$ & $A \star$ & $A \star$ & $B \star$ & $B \star$ & B & $B \star$ & 9 \\
\hline $\begin{array}{l}\text { Westerlund, } \\
\text { 2013(12) }\end{array}$ & C & $A \star$ & $B \star$ & $A \star$ & $A \star$ & $B \star$ & $B \star$ & $A \star$ & $B \star$ & 8 \\
\hline
\end{tabular}




\section{References:}

1. Chen J-C, Brunner RL, Ren H, Wassertheil-Smoller S, Larson JC, Levine DW, et al. Sleep duration and risk of ischemic stroke in postmenopausal women. Stroke; a journal of cerebral circulation. 2008;39(12):3185.

2. Hamazaki Y, Morikawa Y, Nakamura K, Sakurai M, Miura K, Ishizaki M, et al. The effects of sleep duration on the incidence of cardiovascular events among middle-aged male workers in Japan. Scandinavian journal of work, environment \& health. 2011:411-7.

3. Helbig AK, StöckI D, Heier M, Ladwig K-H, Meisinger C. Symptoms of insomnia and sleep duration and their association with incident strokes: findings from the population-based MONICA/KORA Augsburg Cohort Study. PLoS One. 2015;10(7):e0134480.

4. Leng Y, Cappuccio FP, Wainwright NW, Surtees PG, Luben R, Brayne C, et al. Sleep duration and risk of fatal and nonfatal stroke: a prospective study and meta-analysis. Neurology. 2015;84(11):1072-9.

5. Magee CA, Kritharides L, Attia J, McElduff P, Banks E. Short and long sleep duration are associated with prevalent cardiovascular disease in Australian adults. Journal of sleep research. 2012;21(4):441-7.

6. Qureshi Al, Giles WH, Croft JB, Bliwise DL. Habitual sleep patterns and risk for stroke and coronary heart disease: a 10-year follow-up from NHANES I. Neurology. 1997;48(4):904-10.

7. Petrov MER, Letter AJ, Howard VJ, Kleindorfer D. Self-reported sleep duration in relation to incident stroke symptoms: nuances by body mass and race from the REGARDS study. Journal of Stroke and Cerebrovascular Diseases. 2014;23(2):e123-e32.

8. Song Q, Liu X, Zhou W, Wang L, Zheng X, Wang X, et al. Long sleep duration and risk of ischemic stroke and hemorrhagic stroke: the Kailuan Prospective Study. Scientific reports. 2016;6:33664.

9. Tu X, Cai H, Gao Y-T, Wu X, Ji B-T, Yang G, et al. Sleep duration and its correlates in middle-aged and elderly Chinese women: the Shanghai Women's Health Study. Sleep medicine. 2012;13(9):1138-45.

10. Von Ruesten A, Weikert C, Fietze I, Boeing H. Association of sleep duration with chronic diseases in the European Prospective Investigation into Cancer and Nutrition (EPIC)-Potsdam study. PloS one. 2012;7(1):e30972.

11. Amagai Y, Ishikawa S, Gotoh T, Kayaba K, Nakamura Y, Kajii E. Sleep duration and incidence of cardiovascular events in a Japanese population: the Jichi Medical School cohort study. Journal of epidemiology. 2010:0912090122-.

12. Westerlund A, Bellocco R, Sundström J, Adami H-O, Åkerstedt T, Lagerros YT. Sleep characteristics and cardiovascular events in a large Swedish cohort. European journal of epidemiology. 2013;28(6):463-73. 


\begin{tabular}{|c|c|c|c|c|c|}
\hline \multicolumn{6}{|c|}{$\begin{array}{l}\text { Supplementary Table 4. Summary results of the genetic loci of self-reported or derived by } \\
\text { accelerometer sleep duration }\end{array}$} \\
\hline SNP & GX & GX SE & EA & OA & EAF \\
\hline \multicolumn{6}{|c|}{ Self-reported sleep duration } \\
\hline rs915416 & 0.019259 & 0.002495 & $\mathrm{C}$ & G & 0.289947 \\
\hline rs269054 & -0.01364 & 0.002293 & $T$ & $A$ & 0.577924 \\
\hline rs12567114 & -0.01483 & 0.00254 & G & $A$ & 0.724198 \\
\hline rs62120041 & 0.026111 & 0.004575 & $\mathrm{~T}$ & $\mathrm{C}$ & 0.933902 \\
\hline rs374153 & 0.017612 & 0.003103 & C & $T$ & 0.158085 \\
\hline rs75539574 & -0.03625 & 0.004065 & A & $\mathrm{C}$ & 0.914208 \\
\hline rs7556815 & -0.04072 & 0.00274 & G & A & 0.780856 \\
\hline rs12611523 & 0.012635 & 0.002276 & A & $\mathrm{G}$ & 0.545244 \\
\hline rs4538155 & -0.01298 & 0.002374 & C & $\mathrm{T}$ & 0.352574 \\
\hline rs10173260 & -0.01284 & 0.002313 & $\mathrm{~T}$ & $\mathrm{C}$ & 0.393765 \\
\hline rs112230981 & 0.031528 & 0.005228 & $A$ & G & 0.94984 \\
\hline rs17732997 & 0.012935 & 0.002288 & $C$ & $\mathrm{G}$ & 0.569098 \\
\hline rs7644809 & 0.013062 & 0.002301 & $T$ & $C$ & 0.421606 \\
\hline rs13088093 & -0.01627 & 0.002402 & $T$ & $\mathrm{G}$ & 0.663683 \\
\hline rs2192528 & 0.013369 & 0.002269 & $A$ & G & 0.480065 \\
\hline rs17427571 & 0.013826 & 0.002435 & $A$ & $\mathrm{G}$ & 0.684313 \\
\hline rs35531607 & -0.01284 & 0.002273 & $T$ & $C$ & 0.525917 \\
\hline rs13109404 & 0.031204 & 0.004408 & $T$ & $\mathrm{G}$ & 0.928024 \\
\hline rs365663 & 0.014629 & 0.002279 & $A$ & G & 0.545963 \\
\hline rs56372231 & -0.01694 & 0.0024 & $C$ & $\mathrm{~T}$ & 0.665907 \\
\hline rs180769 & 0.012724 & 0.002294 & $\mathrm{~T}$ & $C$ & 0.424698 \\
\hline rs151014368 & -0.01609 & 0.00282 & G & $A$ & 0.793742 \\
\hline rs34556183 & 0.016923 & 0.002523 & $A$ & $\mathrm{G}$ & 0.719606 \\
\hline rs80193650 & -0.01684 & 0.003067 & $A$ & $G$ & 0.837534 \\
\hline
\end{tabular}




\begin{tabular}{|c|c|c|c|c|c|}
\hline rs9382445 & 0.014536 & 0.002334 & $\mathrm{~T}$ & $\mathrm{C}$ & 0.62305 \\
\hline rs2231265 & -0.01496 & 0.002699 & $A$ & $\mathrm{G}$ & 0.227711 \\
\hline rs34731055 & -0.01946 & 0.002948 & $\mathrm{C}$ & $\mathrm{T}$ & 0.81911 \\
\hline rs2079070 & 0.017548 & 0.002566 & $\mathrm{C}$ & $\mathrm{G}$ & 0.264613 \\
\hline rs7806045 & 0.014792 & 0.002626 & $\mathrm{~T}$ & $\mathrm{C}$ & 0.754703 \\
\hline rs330088 & -0.01447 & 0.002277 & $\mathrm{~T}$ & $C$ & 0.452988 \\
\hline rs10973207 & -0.02043 & 0.003124 & $\mathrm{G}$ & $\mathrm{T}$ & 0.842323 \\
\hline rs1776776 & 0.019963 & 0.003411 & $\mathrm{~T}$ & $\mathrm{C}$ & 0.873832 \\
\hline rs12246842 & 0.013395 & 0.002274 & $A$ & G & 0.459815 \\
\hline rs10761674 & 0.012333 & 0.002266 & $C$ & $\mathrm{~T}$ & 0.477334 \\
\hline rs11190970 & 0.015379 & 0.002823 & G & $A$ & 0.798661 \\
\hline rs7915425 & 0.019064 & 0.00299 & $\mathrm{~T}$ & $\mathrm{C}$ & 0.174682 \\
\hline rs1517572 & -0.01464 & 0.002295 & $A$ & $\mathrm{C}$ & 0.419464 \\
\hline rs4592416 & -0.01468 & 0.00227 & $A$ & $G$ & 0.535593 \\
\hline rs174560 & -0.01358 & 0.002437 & $\mathrm{~T}$ & $\mathrm{C}$ & 0.685785 \\
\hline rs12791153 & -0.02355 & 0.004217 & $A$ & $\mathrm{~T}$ & 0.918911 \\
\hline rs1939455 & 0.020425 & 0.003561 & $\mathrm{G}$ & $\mathrm{T}$ & 0.879446 \\
\hline rs1263056 & 0.012799 & 0.002277 & $A$ & G & 0.519099 \\
\hline rs34354917 & 0.013746 & 0.002501 & $\mathrm{C}$ & $A$ & 0.710472 \\
\hline rs11614986 & 0.016379 & 0.002951 & A & $\mathrm{G}$ & 0.820952 \\
\hline rs6575005 & 0.015564 & 0.002642 & $\mathrm{~T}$ & $\mathrm{C}$ & 0.757854 \\
\hline rs61985058 & -0.01859 & 0.003229 & $\mathrm{C}$ & $\mathrm{T}$ & 0.856824 \\
\hline rs11621908 & 0.024095 & 0.004163 & $\mathrm{C}$ & $\mathrm{T}$ & 0.917141 \\
\hline rs8038326 & 0.01592 & 0.002541 & $A$ & $\mathrm{G}$ & 0.72691 \\
\hline rs3095508 & 0.015352 & 0.002304 & $\mathrm{C}$ & $A$ & 0.593529 \\
\hline rs11643715 & -0.0139 & 0.002497 & $\mathrm{C}$ & $G$ & 0.709058 \\
\hline rs9940646 & 0.016946 & 0.002291 & $\mathrm{C}$ & G & 0.577569 \\
\hline rs7503199 & 0.014745 & 0.002564 & $\mathrm{C}$ & $\mathrm{T}$ & 0.734267 \\
\hline rs1991556 & 0.016566 & 0.002724 & G & $A$ & 0.773765 \\
\hline
\end{tabular}




\begin{tabular}{|c|c|c|c|c|c|}
\hline rs12607679 & 0.020139 & 0.002593 & $\mathrm{~T}$ & $\mathrm{C}$ & 0.737717 \\
\hline rs10421649 & -0.0133 & 0.002295 & $\mathrm{~T}$ & A & 0.44303 \\
\hline rs2072727 & 0.013243 & 0.002285 & $\mathrm{~T}$ & C & 0.43617 \\
\hline \multicolumn{6}{|c|}{ Accelerometer derived sleep duration } \\
\hline rs2660302 & 0.041 & 0.006 & A & $\mathrm{T}$ & 0.811 \\
\hline rs113851554 & 0.11 & 0.011 & G & $\mathrm{T}$ & 0.943 \\
\hline rs62158170 & 0.054 & 0.006 & G & A & 0.217 \\
\hline rs17400325 & 0.066 & 0.012 & $\mathrm{~T}$ & $\mathrm{C}$ & 0.958 \\
\hline rs72828540 & 0.041 & 0.005 & $\mathrm{~T}$ & $\mathrm{C}$ & 0.752 \\
\hline rs9369062 & 0.033 & 0.005 & $\mathrm{C}$ & A & 0.292 \\
\hline rs2975734 & 0.027 & 0.005 & $\mathrm{C}$ & $G$ & 0.561 \\
\hline rs13282541 & 0.032 & 0.005 & $\mathrm{C}$ & $\mathrm{T}$ & 0.739 \\
\hline rs2880370 & 0.028 & 0.005 & A & $\mathrm{T}$ & 0.67 \\
\hline rs800165 & 0.028 & 0.005 & $\mathrm{~T}$ & $\mathrm{~T}$ & 0.343 \\
\hline rs10138240 & 0.029 & 0.005 & G & G & 0.514 \\
\hline \multicolumn{6}{|l|}{ Short Sleep } \\
\hline rs7524118 & -0.00576 & 0.001054 & $\mathrm{~T}$ & $\mathrm{C}$ & 0.291624 \\
\hline rs2186122 & -0.00567 & 0.000972 & $A$ & $\mathrm{~T}$ & 0.438434 \\
\hline rs12567114 & 0.006325 & 0.001077 & $\mathrm{G}$ & $A$ & 0.7246 \\
\hline rs2820313 & -0.00601 & 0.00101 & A & $G$ & 0.658888 \\
\hline rs1380703 & -0.00676 & 0.001005 & $A$ & G & 0.616469 \\
\hline rs2863957 & 0.01019 & 0.001161 & $\mathrm{C}$ & $\mathrm{A}$ & 0.781508 \\
\hline rs2014830 & 0.005786 & 0.00105 & $\mathrm{C}$ & $\mathrm{T}$ & 0.698128 \\
\hline rs17005118 & -0.00648 & 0.001087 & G & $\mathrm{A}$ & 0.735064 \\
\hline rs13107325 & -0.01327 & 0.001828 & $\mathrm{C}$ & $\mathrm{T}$ & 0.925472 \\
\hline rs12518468 & -0.00589 & 0.001021 & $\mathrm{~T}$ & $\mathrm{C}$ & 0.671544 \\
\hline rs3776864 & 0.005724 & 0.001019 & A & $\mathrm{C}$ & 0.66721 \\
\hline rs4585442 & -0.00635 & 0.001036 & A & G & 0.688977 \\
\hline rs12661667 & -0.00602 & 0.001087 & $\mathrm{C}$ & $T$ & 0.736505 \\
\hline
\end{tabular}




\begin{tabular}{|l|c|c|c|c|c|}
\hline rs9367621 & 0.005445 & 0.00097 & $\mathrm{~T}$ & $\mathrm{~A}$ & 0.43104 \\
\hline rs9321171 & 0.005354 & 0.000966 & $\mathrm{C}$ & $\mathrm{T}$ & 0.540122 \\
\hline rs11763750 & 0.007212 & 0.001234 & $\mathrm{G}$ & $\mathrm{A}$ & 0.814346 \\
\hline rs1229762 & -0.00724 & 0.001017 & $\mathrm{C}$ & $\mathrm{T}$ & 0.335499 \\
\hline rs60882754 & 0.011304 & 0.002001 & $\mathrm{~A}$ & $\mathrm{~T}$ & 0.938985 \\
\hline rs1607227 & 0.006369 & 0.001055 & $\mathrm{G}$ & $\mathrm{T}$ & 0.704938 \\
\hline rs7939345 & 0.006498 & 0.001182 & $\mathrm{~T}$ & $\mathrm{G}$ & 0.207569 \\
\hline rs17388803 & -0.00983 & 0.001587 & $\mathrm{~A}$ & $\mathrm{C}$ & 0.894352 \\
\hline rs59779556 & 0.005491 & 0.000966 & $\mathrm{~T}$ & $\mathrm{G}$ & 0.553827 \\
\hline rs205024 & 0.00551 & 0.000986 & $\mathrm{C}$ & $\mathrm{T}$ & 0.616724 \\
\hline rs12963463 & 0.007114 & 0.00106 & $\mathrm{C}$ & $\mathrm{T}$ & 0.299425 \\
\hline rs5757675 & 0.006455 & 0.001099 & $\mathrm{G}$ & $\mathrm{T}$ & 0.259528 \\
\hline Long Sleep & -0.00562 & 0.001032 & $\mathrm{G}$ & $\mathrm{A}$ & 0.855558 \\
\hline rs10899255 & -0.01192 & 0.002226 & $\mathrm{C}$ & $\mathrm{G}$ & 0.971827 \\
\hline rs149980149 & 0.004465 & 0.00082 & $\mathrm{C}$ & $\mathrm{T}$ & 0.721799 \\
\hline rs5848 & -0.00501 & 0.00083 & $\mathrm{C}$ & $\mathrm{T}$ & 0.742431 \\
\hline rs62158160 & -0.0047 & 0.000882 & $\mathrm{C}$ & $\mathrm{T}$ & 0.783789 \\
\hline rs72630583 & -0.00598 & 0.001073 & $\mathrm{~A}$ & $\mathrm{G}$ & 0.867766 \\
\hline rs73608603 & -0.01673 & 0.002423 & $\mathrm{C}$ & $\mathrm{T}$ & 0.977027 \\
\hline rs75458655 & 0.003957 & 0.000728 & $\mathrm{G}$ & $\mathrm{A}$ & 0.50028 \\
\hline rs8047395 & \multicolumn{5}{|l|}{ EA effect allele; OA: other allele, EAF: effect allele frequency; GX: the per-allele effect on } \\
\hline standard deviation units of the telomere length; GX SE: standard error of GX.
\end{tabular}




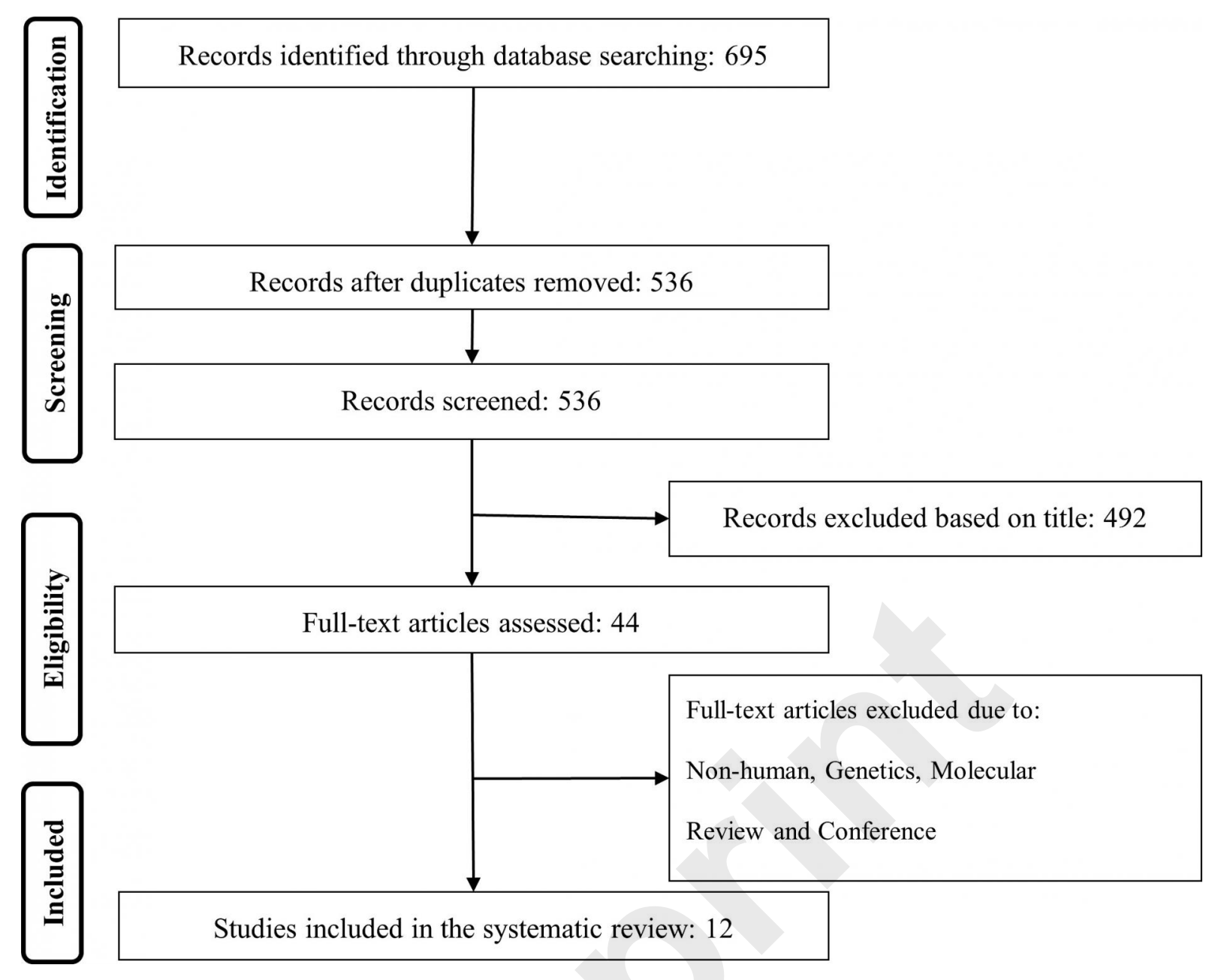

Figure 1. Flow chart of study selection. 
Meta Analysis

Study name

R

Tu 2012 (women) (4)

Amagai 2010 (men) (5)

Amagai 2010 (women) (5)

Hamazaki 2011 (5)

Helbig 2015 (men) (5)

Helbig 2015 (women) (5) 0.68

Leng 2015 (5)

Magee 2011 (5)

Qureshi 1997 (5)

Ruiter Petrov 2014 (5)

Tu 2012 (women) (5)

von Ruesten 2012 (5)

Westerlund 2013 (5)

Amagai 2010 (men) (6)

Amagai 2010 (women) (6) 0.

Chen 2008 (6)

Hamazaki 2011 (6)

Helbig 2015 (men) (6)

Helbig 2015 (women) (6)

Magee 2011 (6)

Ruiter Petrov 2014 (6)

Song 2016 (6)

Tu 2012 (women) (6)

von Ruesten 2012 (6)

Westerlund 2013 (6)
Statistics for each study

\section{Lower Upper}

limit limit

$1.750 \quad 1.483 \quad 2.065$

$\begin{array}{lll}2.000 & 0.929 & 4.306\end{array}$

$\begin{array}{lll}0.970 & 0.390 & 2.411\end{array}$

$\begin{array}{lll}1.840 & 0.229 & 14.765\end{array}$

$\begin{array}{lll}.360 & 0.952 & 1.943\end{array}$

$\begin{array}{lll}680 & 0.398 & 1.163\end{array}$

$\begin{array}{lll}1.180 & 0.910 & 1.530\end{array}$

$1.540 \quad 1.358 \quad 1.747$

$\begin{array}{lll}1.000 & 0.682 & 1.465\end{array}$

$\begin{array}{lll}1.470 & 0.931 & 2.322\end{array}$

$\begin{array}{lll}1.370 & 1.210 & 1.551\end{array}$

$2.060 \quad 1.181 \quad 3.593$

$\begin{array}{lll}1.050 & 0.808 & 1.36\end{array}$

$\begin{array}{lll}1.130 & 0.630 & 2.028\end{array}$

$\begin{array}{lll}0.680 & 0.391 & 1.183\end{array}$

$\begin{array}{lll}1.140 & 0.974 & 1.335\end{array}$

$\begin{array}{lll}0.960 & 0.299 & 3.081\end{array}$

$\begin{array}{lll}0.920 & 0.700 & 1.210\end{array}$

$\begin{array}{lll}1.250 & 0.912 & 1.714\end{array}$

$1.250 \quad 1.136 \quad 1.375$

$\begin{array}{lll}1.220 & 0.821 & 1.813\end{array}$

$\begin{array}{lll}0.920 & 0.808 & 1.047\end{array}$

$\begin{array}{lll}1.160 & 1.047 & 1.28\end{array}$

$1.130 \quad 0.721 \quad 1.772$

$0.950-0.791$

$\begin{array}{lll}0.950-0.791 & 1.141\end{array}$

$\begin{array}{ll}1.081 & 1.304\end{array}$

\section{-Value}

0.000

0.076

0.948

0.566

0.091

0.159

0.212

0.000

1.000

0.099

0.000

0.011

0.715

0.682

0.172

0.104

0.945

0.550

0.166

0.000

0.325

0.208

0.005

0.594

0.584

0.000
Risk ratio and $95 \% \mathrm{Cl}$

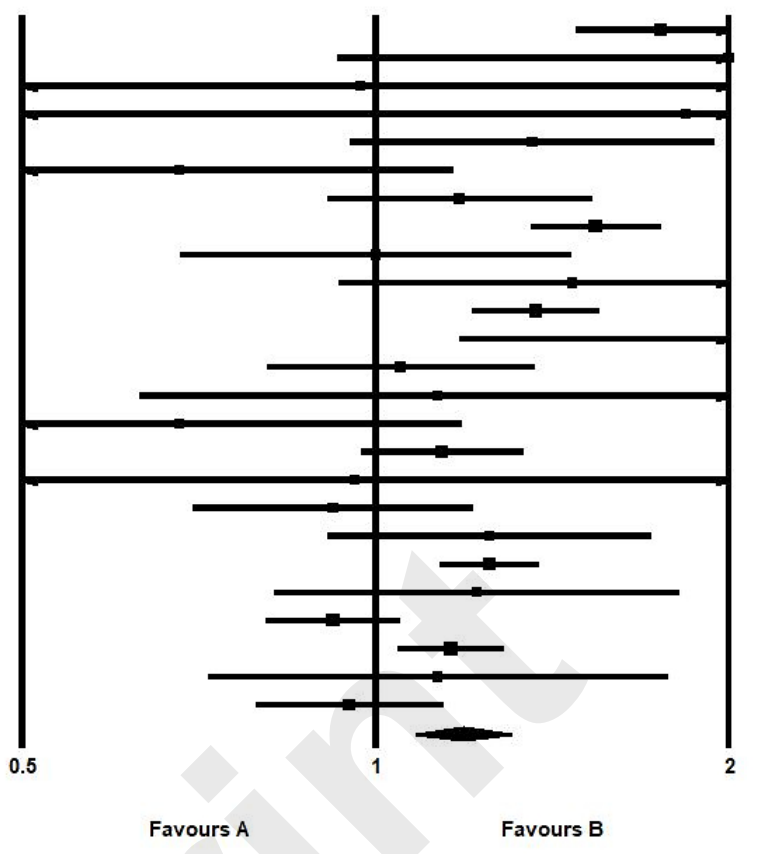

Figure 2: Forest plot of stroke risk associated with $<7$ hours sleep (Favours A) compared to 7-8 hours sleep (Favours B) from 25 studies. Results are expressed as risk ratios and $95 \%$ confidence intervals. Pooled analysis: $p<0.001$; heterogeneity test: $I 2=71.4, p<0.001$. The area of each block is proportional to the weight attributed to each study. 


\section{Meta Analysis}

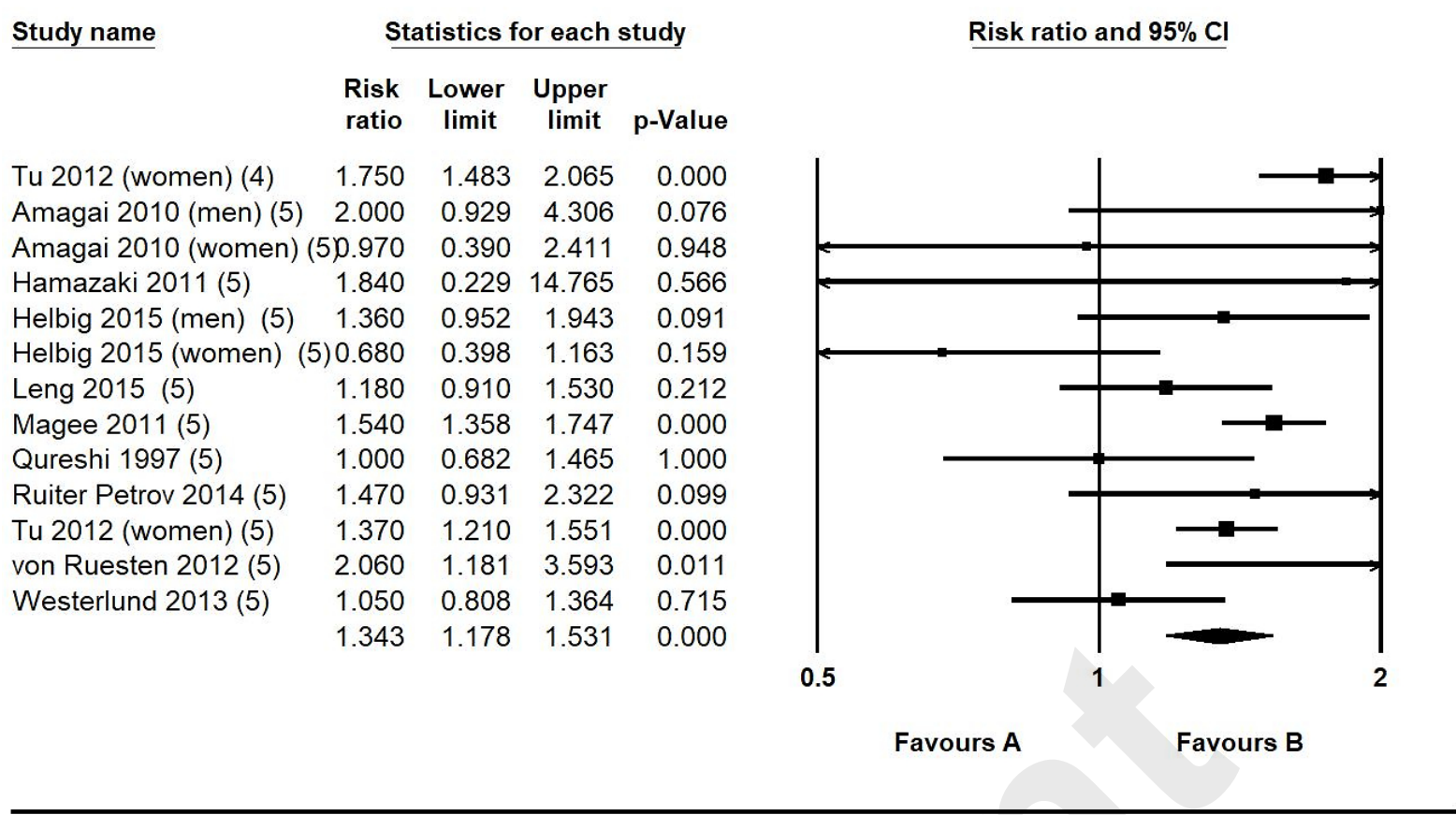

Figure 3: Forest plot of stroke risk associated with $<5$ hours sleep (Favours $A$ ) compared to 7-8 hours sleep (Favours B) from 13 studies. Results are expressed as risk ratios and $95 \%$ confidence intervals. Pooled analysis: $p<0.001$; heterogeneity test: $I 2=58.4, p<0.001$. The area of each block is proportional to the weight attributed to each study. 


\section{Meta Analysis}

\begin{tabular}{lrrrrrr} 
Study name & \multicolumn{5}{c}{ Statistics for each study } \\
\cline { 1 - 5 } & $\begin{array}{r}\text { Risk } \\
\text { ratio }\end{array}$ & $\begin{array}{c}\text { Lower } \\
\text { limit }\end{array}$ & $\begin{array}{c}\text { Upper } \\
\text { limit }\end{array}$ & Z-Value & p-Value \\
& 1.130 & 0.630 & 2.028 & 0.409 & 0.682 \\
Amagai 2010 (men) (6) & 1.680 & 0.391 & 1.183 & -1.365 & 0.172 \\
Amagai 2010 (women) (6) & 0.680 & 1.140 & 0.974 & 1.335 & 1.627 & 0.104 \\
Chen 2008 (6) & 0.960 & 0.299 & 3.081 & -0.069 & 0.945 \\
Hamazaki 2011 (6) & 0.920 & 0.700 & 1.210 & -0.597 & 0.550 \\
Helbig 2015 (men) (6) & 1.250 & 0.912 & 1.714 & 1.387 & 0.166 \\
Helbig 2015 (women) (6) & 1.250 & 1.136 & 1.375 & 4.578 & 0.000 \\
Magee 2011 (6) & 1.220 & 0.821 & 1.813 & 0.984 & 0.325 \\
Ruiter Petrov 2014 (6) & 0.920 & 0.808 & 1.047 & -1.259 & 0.208 \\
Song 2016 (6) & 1.160 & 1.047 & 1.286 & 2.826 & 0.005 \\
Tu 2012 (women) (6) & 1.130 & 0.721 & 1.772 & 0.533 & 0.594 \\
von Ruesten 2012 (6) & 0.950 & 0.791 & 1.141 & -0.548 & 0.584 \\
Westerlund 2013 (6) & 1.078 & 0.983 & 1.183 & 1.598 & 0.110
\end{tabular}

Risk ratio and $95 \% \mathrm{Cl}$

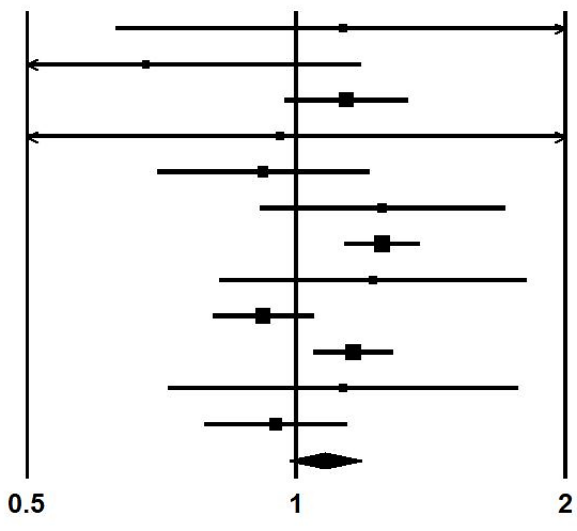

Favours A

Favours B

Figure 4: Forest plot of stroke risk associated with 6 hours sleep (Favours A) compared to 7-8 hours sleep (Favours B) from 12 studies. Results are expressed as risk ratios and 95\% confidence intervals. Pooled analysis: $p=0.110$; heterogeneity test: $I 2=52.6, p=0.016$. The area of each block is proportional to the weight attributed to each study. 
Meta Analysis

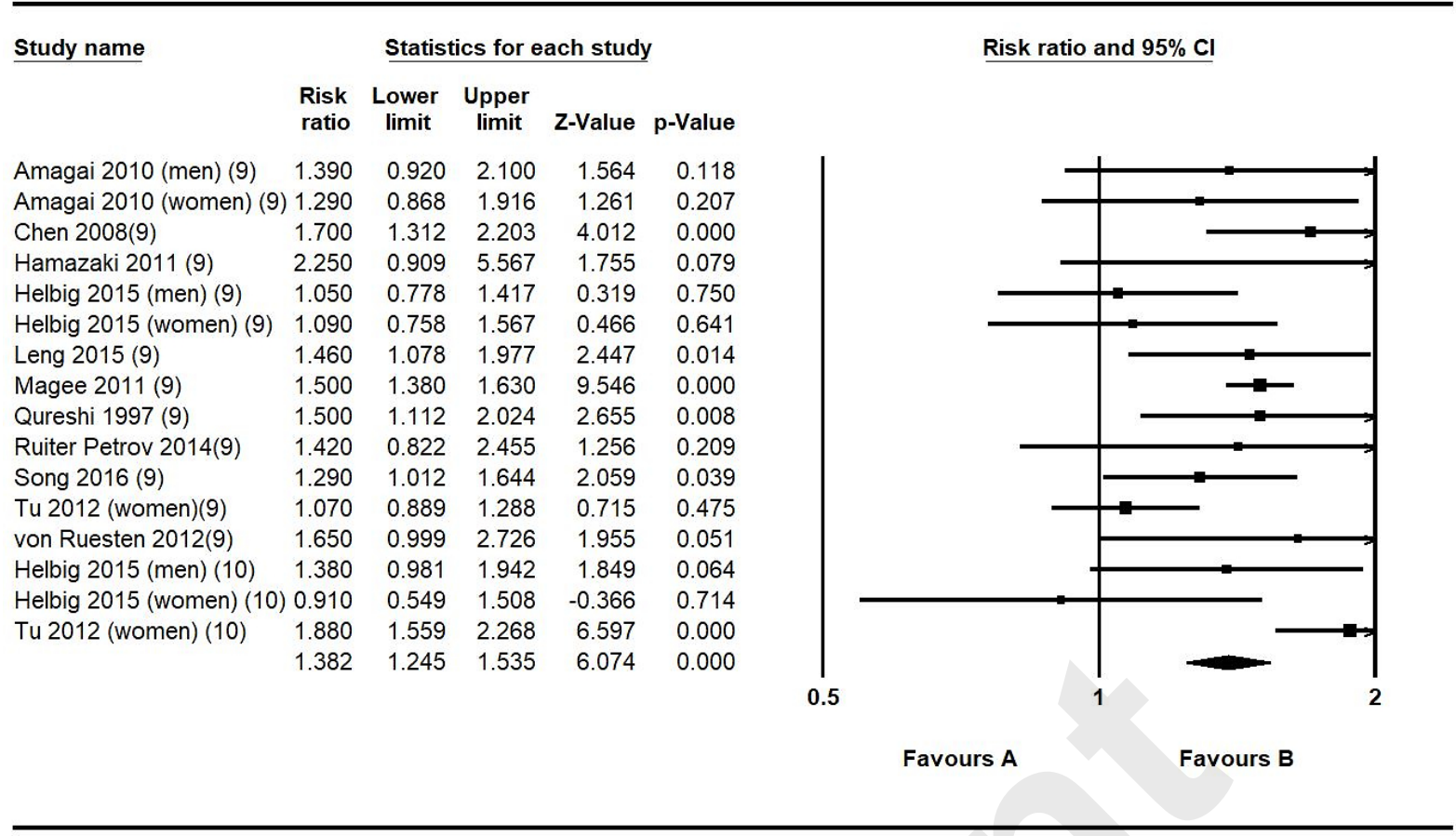

Figure 5: Forest plot of stroke risk associated with $>8$ hours sleep (Favours A) compared to 7-8 hours sleep (Favours B) from 16 studies. Results are expressed as risk ratios and $95 \%$ confidence intervals. Pooled analysis: $p<0.001$; heterogeneity test: $I 2=53.6, p<0.001$. The area of each block is proportional to the weight attributed to each study. 